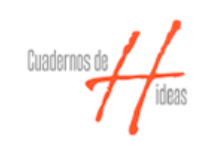

Cuadernos de $\mathrm{H}$ ideas

ISSN: 2313-9048

cuadernosdehideas@perio.unlp.edu.ar

Universidad Nacional de La Plata

Argentina

\title{
Mujeres y participación política en Tlaxcala. Desempeño parlamentario 2013-2017
}

\author{
Cazarín Martínez, Angélica \\ Mujeres y participación política en Tlaxcala. Desempeño parlamentario 2013-2017 \\ Cuadernos de $\mathrm{H}$ ideas, vol. 12, núm. 12, 2018 \\ Universidad Nacional de La Plata, Argentina \\ DOI: https://doi.org/10.24215/23139048e014
}

Esta obra está bajo una Licencia Creative Commons Atribución-NoComercial-SinDerivar 4.0 Internacional. 
Artículos

\title{
Mujeres y participación política en Tlaxcala. Desempeño parlamentario 2013-2017
}

\author{
Women and Political Participation in Tlaxcala. Parliamentary \\ performance 2013-2017 \\ Angélica Cazarín Martínez cazarin0202@hotmail.com \\ El Colegio de Tlaxcala, México
}

Cuadernos de H ideas, vol. 12, núm. 12, 2018

Universidad Nacional de La Plata, Argentina

Recepción: 18 Julio 2018

Aprobación: 11 Septiembre 2018

DOI: https://

doi.org/10.24215/23139048e014

CC BY-NC-ND
Resumen: La participación política de las mujeres ha sido un tema de estudio recurrente desde diversas disciplinas y enfoques. Los estudios de género han diversificado su campo de análisis siendo uno de ellos el relativo a las cuotas de participación de mujeres para atender la subrepresentación en los órganos legislativos. En México, las cuotas han transitado del 70/30 por ciento en 2002, pasando por el 60/40 en 2008, hasta lograr la paridad 50/50 en la reforma política de 2014, contexto en el que se destaca el incremento gradual en el desempeño parlamentario de las mujeres diputadas a pesar del número de mujeres en funciones. El presente documento hace un análisis del caso de las mujeres diputadas en la LXI Legislatura del Congreso del Estado de Tlaxcala, con el objetivo principal de conocer las condiciones de equidad sustantiva en las que ejercen sus cargos, así como describir y contextualizar su trabajo y desempeño legislativo en dicho periodo. Palabras clave: participación política de mujeres, desempeño parlamentario, elecciones de diputados locales en Tlaxcala.

Abstract: The political participation of women has been a subject of study of various disciplines and approaches. Gender studies have diversified their field of analysis as one of them, the one related to participation quotas for women to address underrepresentation in legislative bodies. In Mexico, the quotas have gone from 70/30 percent in 2002, going through $60 / 40$ in 2008, until achieving the 50/50 parity in the 2014 political reform, context in which the gradual increase in performance is highlighted. parliamentary committee, despite the number of women in office. This document is an analysis of the case of women deputies in the LXI Legislature of the State Congress of Tlaxcala, with the main objective of meeting the conditions of substantive fairness in exercising their duties and to describe and contextualize their work and qualify legislator in that period.

Keywords: women's political participation, parliamentary performance, elections of local congress in Tlaxcala.

\section{Introducción}

El discurso que busca ser legitimador, constantemente resalta la importancia de la participación de las mujeres en la política; sin embargo, lo cierto es que, desde el surgimiento de las democracias occidentales, su activismo no ha menguado en la lucha contra la exclusión y la discriminación de género. Los avances y logros de las mujeres se deben claramente más a la persistencia para el reconocimiento de sus derechos que a la apertura natural de espacios para su participación. 
Las olas feministas, que comenzaron en 1848 con la Declaración de sentimientos de Seneca Falls(1), pasando por el surgimiento en 1967 del Movimiento de Liberación de las Mujeres, liderado por Jo Freeman (2) y Shulamith Firestone,(3) y la Conferencia Nacional de Mujeres en Houston, Texas en 1977, son apenas algunos de los muchos eventos que a lo largo de la historia han sido espacios emblemáticos para la discusión y exigencia legítima de las mujeres primeramente sobre el reconocimiento al sufragio, buscando crear y modificar todos aquellos obstáculos legales que garantizarán la igualdad de género; en segundo lugar, la contundente exigencia de las mujeres incorporó temas tan importantes como el derecho al trabajo, sexualidad y familia, entre otros; estas exigencias han avanzado hasta nuestros días, ubicando temas tan trascendentales como la violencia política en contra de las mujeres, como una variante altamente frecuente en los procesos político-electorales, que en el caso mexicano está siendo objeto de análisis para su probable legislación, pues tal y como afirma Teresita De Barbieri:

"la subordinación que afecta a todas o casi todas las mujeres es una cuestión de poder, pero éste no se ubica exclusivamente en el Estado y en los aparatos burocráticos. Sería un poder múltiple, localizado en muy diferentes espacios sociales, que puede incluso no vestirse con los ropajes de la autoridad, sino con los más nobles sentimientos de afecto, ternura y amor".(4)

En este contexto, la inclusión de los sistemas de cuotas de género tuvo un impacto fundamental en la transformación de los sistemas electorales y la participación de la mujeres en la política, especialmente en el poder legislativo y las formas de representación política.(5) Los abundantes estudios sobre dicho impacto sin duda aportan elementos que destacan la relevancia de la inclusión de las cuotas, incrementando no sólo la representación de mujeres en los legislativos, sino también la inclusión de nuevos temas en las agendas y consecuentemente en el rendimiento parlamentario.(6)

Si bien la inclusión de las cuotas de género ha tenido inicialmente una buena intención, lo cierto es que en la realidad los mecanismos internos de selección de candidaturas y las dinámicas internas de los partidos políticos (entre otras cosas), mostró la insuficiencia de las mismas. En México, la proporción de las cuotas fue del $70 / 30$ por ciento en 2002, pasando por el 60/40 en 2008, contexto en el que se presentaron casos lamentables como el de "las Juanitas",(7) hecho que fue apenas una muestra de las muchas formas en que los partidos podían encontrar vías para evadir el cumplimiento de cuotas. La última reforma política en México (2014) establece como obligatorio no sólo el cumplimiento de la paridad 50/50 en el registro de candidaturas, sino también la obligatoriedad en el registro de la suplencia del mismo género. Si bien ha sido un importante logro que garantiza el acceso de las mujeres a cargos de elección, lo cierto es que dicho escenario ha empezado a evidenciar que, a pesar de ser una norma obligatoria, todavía al interior de los partidos políticos persiste una cultura machista y misógina que busca obstaculizar la participación plena de las mujeres en la toma de decisiones en la vida pública del país.(8) 
Es así que a 65 años del reconocimiento del sufragio femenino en México (1953), los resultados muestran que la participación y presencia de las mujeres es aún insuficiente. En este contexto, analizar el caso de la participación de las mujeres diputadas en los congresos locales es apenas un ejemplo de las condiciones de equidad sustantiva en la que ejercen sus cargos, así como describir y contextualizar su desempeño legislativo.

La metodología empleada para la realización del presente trabajo fue mixta, en la medida en que se incluye un trabajo cuantitativo y cualitativo; el artículo tiene un carácter descriptivo que aborda el fenómeno no sólo de la participación política de las mujeres en el legislativo en el estado de Tlaxcala, concretamente de la LXI legislatura, sino que también muestra el rendimiento parlamentario de las diputadas en dicho periodo. La realización del artículo incluyó tanto trabajo de gabinete como información documental, solicitada en su momento al propio Congreso del Estado; paralelamente, se realizaron entrevistas a seis de nueve exdiputadas de la LXI Legislatura, el resto (tres), en algunos casos, no residían ya en la entidad y otras no respondieron positivamente a la aplicación del instrumento; esto con el propósito de argumentar con mayor consistencia los resultados presentados en este trabajo.

El artículo se desarrolla bajo tres premisas fundamentales: a) existen perfiles diferenciados entre diputados y diputadas (edad, nivel educativo y experiencia política); b) persiste una distribución inequitativa del poder, ya que los diputados conservan los cargos relevantes en el congreso, así como las comisiones estratégicas, asignando a las diputadas cargos de menor trascendencia en los órganos internos de gobierno; y c) persiste la propuesta de agendas legislativas diferenciadas entre géneros; es decir, la asignación de temas relacionados con el rol de género. En este contexto, el artículo se divide en siete apartados: 1) mujeres y procesos políticos en Tlaxcala como una forma de contextualizar el activismo político de las mujeres en la entidad; 2) selección de candidatos, resultados y relación ejecutivo-legislativo de la LXI legislatura; 3) nivel académico y perfil profesional, de las y los legisladores; 4) desempeño parlamentario y distribución del poder en los órganos de gobierno al interior del legislativo local; 5) agenda legislativa y desempeño parlamentario; 6) retos y perspectivas; y 7) conclusiones.

Es importante destacar que, en el estado de Tlaxcala, los resultados electorales han sido notorios a nivel nacional, ya que la entidad ha sido una de las pocas donde se ha experimentado la alternancia con los entonces tres partidos políticos más importantes (PAN, PRI y PRD), hasta antes del surgimiento del partido político Movimiento de Regeneración Nacional (MORENA) (9) en 2014; y es en las elecciones tanto federales como locales donde cada vez son más y más reducidos los márgenes de victoria en contextos de alta competitividad. En Tlaxcala, la participación de las mujeres ha sido importante; la primera alternancia se presentó en la elección de 1998 ganando la gubernatura el ex priista Alfonso Sánchez Anaya (1999-2005), encabezando una coalición entre PRD-PT y PVEM; la segunda alternancia se presentó en 2004, ganando la gubernatura Héctor Israel Ortiz Ortiz (2005-2011), candidato del PAN también 
recién salido de las filas del PRI; la tercera y última alternancia hasta ahora a nivel de gubernatura, se presentó en la elección de 2010, resultando en el retorno del PRI al gobierno del estado, encabezado por Mariano González Zarur (2011-2017), a quien habría de sucederlo Marco Antonio Mena Rodríguez (2017-2021), también priista y actual gobernador de la entidad (2018). Desde 2004 a la última en 2016, las elecciones han incluido a mujeres en la contienda.

\section{Mujeres y procesos políticos en Tlaxcala}

Lejanos son los tiempos en los que el estado de Tlaxcala (al igual que otros del país), era considerado como reserva de votos para el Partido Revolucionario Institucional (PRI); hoy, los contextos de alta competencia y competitividad, a los que se suma un fuerte descontento ciudadano respecto a los eventos de corrupción e impunidad, y las crisis sistémicas que aquejan al país, son el perfecto caldo de cultivo para la incertidumbre. En Tlaxcala, elección tras elección y en todos los niveles, el PRI obtenía el triunfo prácticamente de "carro completo"; no existía una verdadera competencia y la débil oposición, al no lograr triunfos contundentes, no era un verdadero contrapeso a las decisiones trascendentales de política pública para la entidad.

Fue a partir de la elección presidencial en México de 1988 en que se sentaron las bases para lo que sería un lento proceso de transformación política, tanto a nivel nacional como local; en este contexto, Tlaxcala no sería la excepción. Las alternancias políticas empezaban a presentarse en varios lugares del país con un importante cambio en la conformación del sistema de partidos, dando paso a una nueva etapa de mayor participación y competencia política.

Como se ha mencionado, Tlaxcala era una de las pocas entidades en donde ha habido gobiernos de alternancia con los tres partidos más importantes hasta entonces (PRI, PAN y PRD), antes de MORENA; sin embargo, y a pesar de las alternancias, persiste una característica particular que remite a un complejo entramado de élites familiares que en poco más de cuatro décadas han gobernado la entidad, derivándose (salvo alguna excepción) en un selecto grupo de colaboradores del entonces gobernador Emilio Sánchez Piedras (1975-1981), constituyendo una clase política arraigada hasta nuestros días. Es así que, al ser un estado con particularidades locales de clases y familias en la conformación de su clase política, los procesos políticos y electorales no pueden ser explicados sin atender a dichos contextos, coyunturas y actores, aspectos asociados indisolublemente a la realidad local.

Es importante destacar que la participación política de las mujeres en la entidad ha sido muy importante: Tlaxcala fue el segundo estado del país gobernado por una mujer: Beatriz Paredes Rangel, mujer tlaxcalteca con una importante trayectoria política a nivel local y nacional, gobernadora del estado de Tlaxcala (1987-1992);(10) diputada en el congreso local (1975-1978); diputada federal en tres ocasiones: LI (1979-1982), LIII (1985-1988) y LVIII (2000-2003) Legislaturas; senadora en la LVII 
(1997-2000) y LXIV (2018-2021) Legislaturas; Presidenta del PRI Nacional (2007-2011); subsecretaria en la Secretaría de Gobernación en tres ocasiones y Subsecretaria de la Reforma Agraria; embajadora de México en Cuba (1993-1994), Embajadora en Brasil (2013-2016). A Beatriz Paredes se le considera incluso actualmente, como una de las principales estrategas de la política en Tlaxcala.

En este escenario, el activismo de las mujeres en Tlaxcala ha sido importante sobre todo a nivel gubernatura; sin embargo, desde que Paredes Rangel fuera gobernadora, ninguna otra mujer ha ocupado el cargo a pesar de los diversos esfuerzos de varias por lograrlo. Desde 1992, y con excepción de la elección de 1998, en todas se ha contendido entre una y hasta tres mujeres (ver Cuadro 1). En los cinco procesos electorales a partir de 1992 para elegir gobernador, han triunfado hombres: José Antonio Álvarez Lima (1992-1998); Alfonso Sánchez Anaya (1998-2004); Héctor I. Ortiz Ortiz (2004-2010); Mariano González Zarur (2010-2016) y Marco Antonio Mena Rodríguez (2016-2021) (11)(ver Gráfica1).

\section{Cuadro 1.}

Candidatos/as a Gobernador 1992-2016, Tlaxcala

\begin{tabular}{|c|c|c|c|c|}
\hline 1992 & 1998 & 2004 & 2010 & 2016 \\
\hline $\begin{array}{l}\text { José Antonio } \\
\text { Álvarez Lima } \\
\text { (PRI) }\end{array}$ & $\begin{array}{l}\text { Joaquín } \\
\text { Cisneros } \\
\text { Fernández (PRI) }\end{array}$ & $\begin{array}{l}\text { Mariano } \\
\text { González } \\
\text { Zarur } \\
\text { (PRI-PVEM) }\end{array}$ & $\begin{array}{l}\text { Mariano González } \\
\text { Zarur (PRI-PVEM) }\end{array}$ & $\begin{array}{l}\text { Marco Antonio Mena } \\
\text { Rodríguez } \\
\text { (PRI-PVEM-PANAL-PS) }\end{array}$ \\
\hline $\begin{array}{l}\text { Ubaldo } \\
\text { Lander } \\
\text { Corona (PRD) }\end{array}$ & $\begin{array}{l}\text { Alfonso } \\
\text { Sánchez Anaya } \\
\text { (PRD-PT-PVEM) }\end{array}$ & $\begin{array}{l}\text { Héctor Ortiz } \\
\text { Ortiz } \\
\text { (PAN-PCD-PT) }\end{array}$ & $\begin{array}{l}\text { Minerva Hernández } \\
\text { Ramos } \\
\text { (PRD-PT-Convergencia) } \\
\text { Declinó a favor de la } \\
\text { cand. Del PAN }\end{array}$ & $\begin{array}{l}\text { Lorena Cuéllar } \\
\text { Cisneros (PRD) }\end{array}$ \\
\hline $\begin{array}{l}\text { no registró } \\
\text { candidato } \\
\text { (PAN) }\end{array}$ & $\begin{array}{l}\text { Jorge Moreno } \\
\text { Durán (PAN) }\end{array}$ & $\begin{array}{l}\text { María del } \\
\text { Carmen } \\
\text { Ramirez } \\
\text { (PRD-Mov. } \\
\text { Ciudadano) }\end{array}$ & $\begin{array}{l}\text { Adriana Dávila } \\
\text { Fernández } \\
\text { (PAN-PANAL-PAC) }\end{array}$ & $\begin{array}{l}\text { Adriana Dávila } \\
\text { Fernández (PAN) }\end{array}$ \\
\hline $\begin{array}{l}\text { Teresita } \\
\text { Castillo } \\
\text { Tzompantzi } \\
\text { (PARM) }\end{array}$ & & & $\begin{array}{l}\text { Rosalía Peredo Aguilar } \\
\text { (PS) }\end{array}$ & $\begin{array}{l}\text { Edilberto Algredo } \\
\text { Jaramillo (Movimiento } \\
\text { Ciudadano) }\end{array}$ \\
\hline \multirow[t]{4}{*}{$\begin{array}{l}\text { Óscar } \\
\text { Alvarado } \\
\text { Alcántara } \\
\text { (PPS) }\end{array}$} & & & & $\begin{array}{l}\text { Martha Palafox } \\
\text { Gutiérrez (MORENA) }\end{array}$ \\
\hline & & & & $\begin{array}{l}\text { Marco Antonio } \\
\text { Hernández Morales } \\
\text { (PES) }\end{array}$ \\
\hline & & & & $\begin{array}{l}\text { Felipe Hernández } \\
\text { Hernández (PAC) }\end{array}$ \\
\hline & & & & $\begin{array}{l}\text { Jacob Hernández } \\
\text { Corona } \\
\text { (Independiente) }\end{array}$ \\
\hline
\end{tabular}

Fuente: Elaboración propia, con base en el Instituto Electoral de Tlaxcala-Instituto Tlaxcalteca de Elecciones. 


\section{Gráfica 1.}

Comportamiento de los tres partidos políticos más importantes en las elecciones a Gobernador (PAN, PRI Y PRD), 1992-2016, Tlaxcala

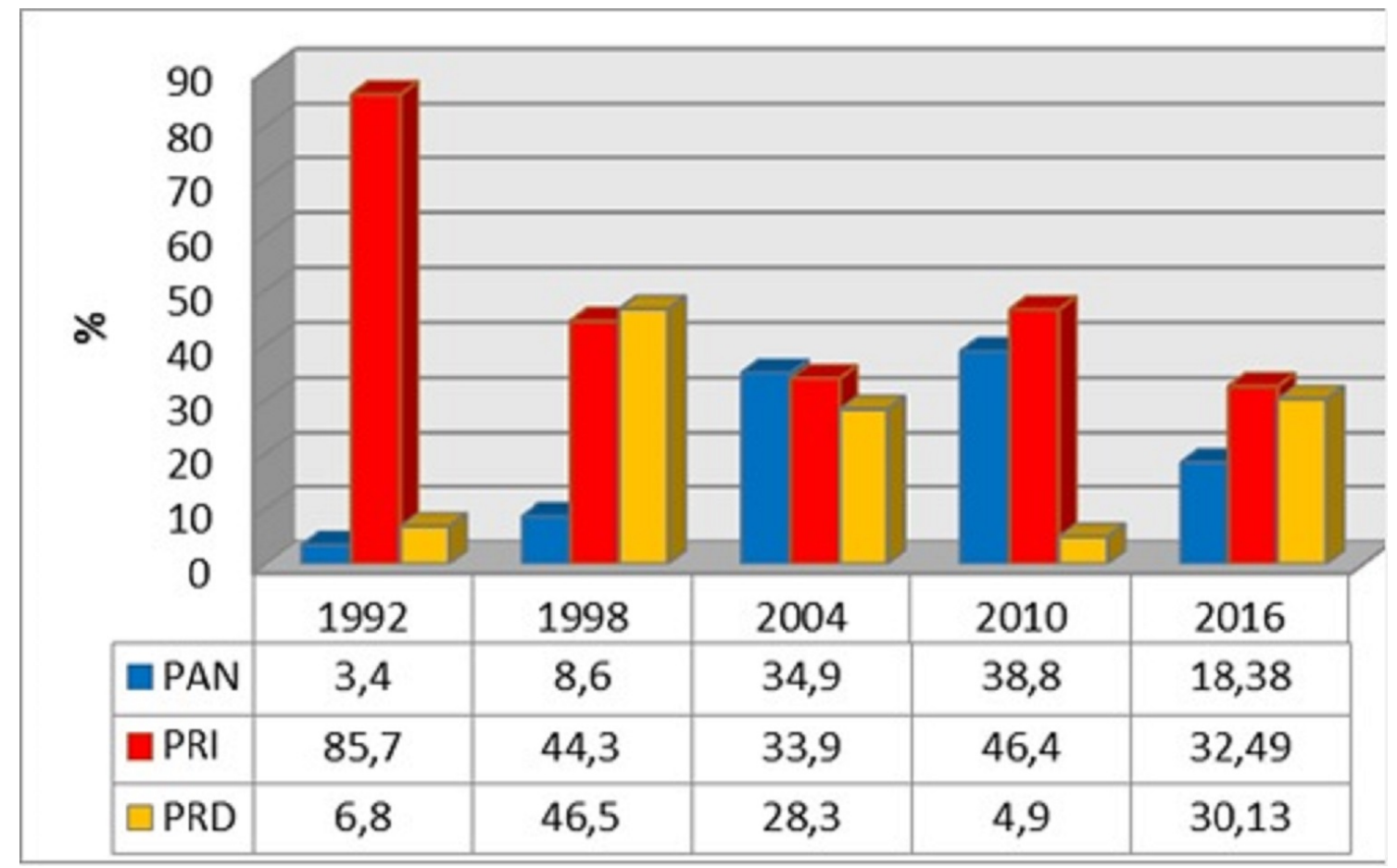

Fuente: elaboración propia, con base en el Instituto Electoral de Tlaxcala-Instituto Tlaxcalteca de Elecciones. Si bien en las elecciones de 1992, 2010 y 2016 contendieron más candidatos de otros partidos e independientes por la gubernatura de la entidad, el propósito de esta gráfica es mostrar, tal como lo enuncia el título, el comportamiento de los tres partidos más importantes hasta el momento en la entidad. En 2016, si bien contendió MORENA con su candidata Martha Palafox, esta obtuvo apenas el 6.33\% de los votos.

Asimismo, la participación de las mujeres en el congreso local a lo largo del tiempo, no dista de una clara inequidad, a pesar de las cuotas establecidas por la ley para ello. En 1857, la conversión del territorio de Tlaxcala en estado libre y soberano de la federación, permitió el inicio del primer periodo de sesiones del congreso local, asumiendo la primera gubernatura de la entidad Guillermo Valle, en el mes de junio de ese año, y quien fuera Gobernador por cuatro meses pues se disolvió el congreso; sin embargo, y al no ser objeto del presente capítulo el recuento del periodo de inestabilidad política y social que aquejó a la entidad, antes y varios años después de la Revolución de 1910, destacamos que fue hasta 1968 que María de los Ángeles Grant Munive(12) quien ocuparía por primera vez el cargo de diputada local, 15 años después (1953) de que se reconociera constitucionalmente el derecho al sufragio de las mujeres en México. Desde entonces, la participación de las mujeres como diputadas en el Congreso de Tlaxcala ha sido claramente insuficiente e irregular, oscilando entre una y nueve, siendo la LXI Legislatura (2013-2017) donde más mujeres diputadas hubo en el congreso, cantidad que disminuyó en la siguiente legislatura (LXII), que irónicamente y después de haberse promulgado constitucionalmente la paridad 50/50 para hombres y mujeres en la Reforma Política de 2014, participan apenas siete de ellas (ver Gráfica 2). 
Gráfica 2.

Congreso del Estado de Tlaxcala, diputadas, 1968-2018

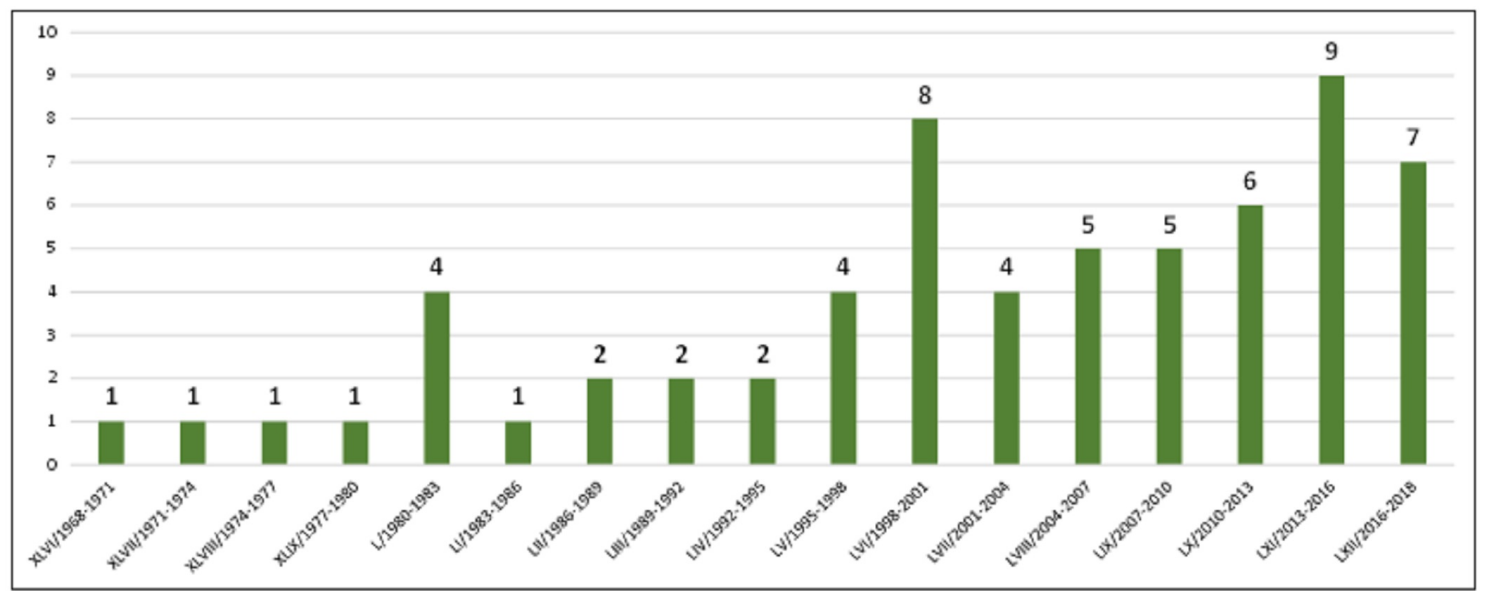

Fuente: elaboración propia, con base en Legislaturas del Honorable Congreso del Estado de Tlaxcala. Es importante destacar que los periodos legislativos duran tres años; sin embargo, concluyen el 31 de diciembre del año en curso e inician funciones el $1^{\circ}$ de enero del año siguiente, siendo un caso extraordinario el de la LXII Legislatura Local, que duraría en funciones del 31 de diciembre de 2016 al 29 de agosto de 2018, conforme a lo dispuesto en los artículos 38, 39 y 40 de la Constitución Política Local; y 16, 17, 18 y 20 de la Ley Orgánica del Poder Legislativo del Estado de Tlaxcala.

Gráfica 3.

Padrón Electoral/ Distribución de Ciudadanos por Sexo, Tlaxcala

Fuente: elaboración propia, con base en el Instituto Nacional Electoral (2017).

A pesar de que en Tlaxcala (como en el resto del país) el padrón está compuesto por 921,915 ciudadanos, de los cuales el $52.46 \%$ son mujeres (más del cincuenta por ciento) (ver Gráfica 3), lo cierto es que en el ámbito político, el género femenino continúa siendo sub-representado, debido a que la participación de las mujeres se ubica fundamentalmente en las estructuras de base de los partidos políticos; o en su caso, está determinada por señalamientos legales de carácter obligatorio, como lo fueron las llamadas "cuotas de género".

Pese a las claras deficiencias, es posible encontrar mujeres en Tlaxcala que, dedicadas a la política, presenten un trabajo importante no sólo por el hecho de contender por cargos de elección popular (en este caso diputaciones), sino que el esfuerzo se traduce además en resultados 
cuantificables en relación al rendimiento parlamentario, que es el caso que nos ocupa de las diputadas en la LXI Legislatura Local.

\section{Selección de candidatos, resultados y relación ejecutivo- legislativo}

Uno de los principales problemas que han enfrentado los partidos políticos, derivado de la Reforma Política de 2014, fue justamente el relativo al cumplimiento de la paridad (50/50) alcanzada por dicha reforma. En el estado de Tlaxcala, el artículo 10 de la Ley de Instituciones y Procedimientos Electorales, establece que:

"Los partidos politicos y las coaliciones garantizarán la igualdad de género en proporciones de cincuenta por ciento en candidaturas propietarias y suplentes en las elecciones ordinarias y extraordinarias de diputados locales y de ayuntamientos; del mismo modo, dicha igualdad deberá cumplir las planillas de candidatos independientes a los ayuntamientos. Las fórmulas de candidatos deberán ser integradas por personas del mismo género. Las listas por el principio de representación proporcional se integrarán de manera alternada con candidaturas de género distinto. Ningún partido político o coalición excederá del cincuenta por ciento de candidatos de un mismo género".(13)

Además, la Ley de Partidos Políticos para el Estado de Tlaxcala, en su art. 52, en su apartado XX, establece como obligación: "Garantizar la paridad de género en candidaturas a diputados locales por los principios de mayoría relativa $y$ de representación proporcional, planillas de candidatos a integrantes de los Ayuntamientos, y candidatos a presidentes de comunidad tanto propietarios como suplentes"(14); donde el Instituto Tlaxcalteca de Elecciones (ITE) deberá acatar dichas disposiciones legales para hacer los registros de las candidaturas.

En este contexto, los partidos políticos deben también acatar dicha normatividad, o se verán afectados con sanciones e incluso con la posibilidad de pérdida del registro. Así, el PRI establece en su Reglamento para la Elección de Dirigentes y Postulación de Candidaturas, en el artículo 42, en el apartado IX: "Asegurar la paridad de género y la inclusión de jóvenes en los términos que señale la Constitución Política de los Estados Unidos Mexicanos, las leyes de la materia y los Estatutos"; derivado de ello, los órganos directivos del partido (CEN y CDE) ajustan los métodos de selección de candidatos/as: primeramente, a través de la aplicación de encuestas y, finalmente, a través de las convenciones de delegados.

La selección de candidatos en el PAN es a través de convenciones distritales para diputados locales, municipales para presidentes municipales, y estatal para designar candidatos de representación proporcional. El PAN, a través del Comité Directivo Estatal (CDE), enfrentó también el problema de buscar candidatas mujeres, pues de 30 inscritos, sólo había ocho mujeres. Asimismo, el PRD, en sus estatutos (2015), en el artículo 275, establece que:

"Las y los candidatos para elecciones... (de) diputaciones locales... por el principio de mayoria relativa, presidencias municipales, sindicaturas y regidurias por el principio de mayoría relativa, se elegirán mediante el método que el consejo respectivo determine, mediante la decisión del 60 por ciento de las y los consejeros presentes. Los métodos de selección a realizarse podrán ser los siguientes: a) por votación universal, directa y secreta abierta a la ciudadania del ámbito correspondiente; b) por votación universal, directa y secreta de los afliados del ámbito correspondiente; c) por votación de los consejeros respectivos de la instancia correspondiente; d) por candidatura única presentada ante el Consejo o e) por votación de los representantes seccionales en el ámbito correspondiente". 
Los resultados fueron: de 73 fórmulas que se registraron, sólo ocho fueron para mujeres. Es claro que la paridad (50/50) que establece la Reforma Política de 2014 derivó en una complejidad más a salvar por parte de los partidos políticos; para ser más claros, es un reto de "ida y vuelta" (porque no sólo significa la adopción de nuevas formas y métodos en la vida interna de los partidos, sino también un reto importante para las mujeres) en la idea de romper lo que analistas de género definen como "techos de cristal"(15) y "suelos pegajosos",(16) que no son otra cosa más que los propios prejuicios y autocensura que las mujeres se imponen para no participar como entes activas de la vida pública del país y de Tlaxcala. Seguramente, los resultados e impactos de la reforma serán mayormente visibles en la próxima elección de 2018, donde habrán de implementarse completamente. En este contexto, algunas de las exdiputadas opinaron que:

"Hubo muchas trabas para poder ser candidata del Partido Acción Nacional, ya que, a pesar de estar establecido en la ley, tuve que renunciar a un cargo previo para poder participar, a pesar de renunciar, no aceptaban mi renuncia en tiempo y forma" (Entrevistas, 2017).

"Las mujeres continuan teniendo limitantes en la participación de una candidatura, ya que estas se ofrecen principalmente a varones" (Entrevistas, 2017).

"Mediante acuerdos, y bajo el marco de la ley conforme a la paridad de género se brindaron las condiciones para poder participar sin tener que llegar a conflictos o fricciones" (Entrevistas, 2017).

"Si, la sociedad, los actores politicos y las mismas mujeres no están preparadas o empoderadas para representar un cargo de elección" (Entrevistas, 2017).

"Fue por cuestiones machistas o de interés que un compañero teniendo conocimiento de los lineamientos que rigen al partido en el que militaba, apela al resultado que le desfavorecía. Por condiciones de falta de apertura, conocimiento, voluntad y de machismo o misoginia se dieron estos sucesos" (Entrevistas, 2017).

Por otra parte, es importante destacar que para el caso que nos ocupa, en los resultados electorales de las elecciones a diputados locales de 2013 salieron triunfadoras cinco diputadas por mayoría relativa, todas encabezando la coalición entre el PRI y PVEM "Bienestar para todos": Cecilia Sampedro Minor Distrito X, Juana de Guadalupe Cruz Bustos Distrito II, María Angélica Zárate Flores Distrito XI y María Antonieta Maura Stankiewicz Ramírez Distrito XV; y cuatro por representación proporcional: por el PAN María de Lourdes Huerta Bretón, por el PRD Eréndira Elsa Carlota Jiménez Montiel, por el PAC Evangelina Paredes Zamora y por el PS Patricia Zenteno Hernández (ver Cuadro 2). 


\section{Cuadro 2.}

Resultados de las elecciones de Diputados Locales, 2013, Tlaxcala

\begin{tabular}{|c|c|c|c|c|c|c|c|c|c|c|c|c|c|c|c|c|}
\hline Dastritos & Secciones & $\begin{array}{c}\text { Casilts } \\
\text { instaladis }\end{array}$ & $\begin{array}{c}\text { Lista } \\
\text { Nomingl }\end{array}$ & PAN & $\begin{array}{l}\text { 㗉 } \\
\text { pro }\end{array}$ & $\frac{P T}{\mu}$ & $\begin{array}{l}Y \\
M C\end{array}$ & 2 & $\begin{array}{l}\mathrm{PAC} \\
\mathrm{PAC}\end{array}$ & P. & $\frac{(1)}{\text { per }}$ & $\frac{8}{\text { P.VEM. }}$ & $\begin{array}{l}28 \\
\text { v. Nubs }\end{array}$ & $\sqrt{\text { v. vilidos }}$ & V. Emitida & Particiación \\
\hline Tilaxcelo Centro Sur & 23 & 67 & 46673 & 4531 & 3185 & 2089 & 872 & $14 \mathrm{M}$ & 4319 & 841 & 5223 & 1053 & 1212 & 23967 & 25179 & $53.95 \mathrm{x}$ \\
\hline II Tlaxcala Norte & 31 & 68 & 45862 & 3597 & 4666 & 1919 & 2098 & 3585 & 3340 & 2113 & 5008 & 1376 & 1672 & 2702 & 29374 & $64.05 \%$ \\
\hline Contla de Juan Cuamatri & 28 & 66 & 43462 & 4634 & 2967 & 3301 & 653 & 1833 & 5175 & 2153 & 6376 & 920 & 1241 & 20012 & 29253 & $67.31 \%$ \\
\hline N Chiautempan Norte & 26 & 65 & 42294 & 5310 & 4007 & 874 & 732 & 1414 & 2056 & 1183 & 5260 & 580 & 1219 & 23436 & 24655 & $58.29 \mathrm{x}$ \\
\hline$V$ Teclocholico & 22 & 59 & 41535 & 5962 & 5895 & 2549 & 444 & 926 & 1024 & 2618 & 5591 & 1690 & 1307 & 26699 & 28006 & $67.43 \mathrm{X}$ \\
\hline VI San Pablo del Monte & 15 & 55 & & 2984 & $m 01$ & 4778 & 272 & 406 & 206 & 1612 & 6268 & 396 & 1042 & 26430 & 27472 & 67.595 \\
\hline Vili papalocta & 24 & 62 & & 5726 & 4414 & 775 & 7022 & 759 & 74 & 372 & 5272 & 383 & 976 & 25484 & 26050 & $65.90 x$ \\
\hline Vilizacaneko & 21 & 62 & 42554 & 4851 & 12403 & 599 & 1073 & 1388 & 892 & 995 & 3969 & 237 & 1038 & 26467 & 27505 & $64.64 \mathrm{~K}$ \\
\hline$\alpha$ Teperanco & 31 & 65 & 42518 & 1604 & 5028 & 1977 & 1800 & 8999 & 1504 & 3043 & 5202 & 672 & 1185 & 29838 & 31023 & $72.96 x$ \\
\hline Xativeas & 28 & 60 & & 1372 & 9029 & 1712 & 1353 & 3161 & 1285 & 1063 & 6729 & 2728 & 1376 & 22334 & 29810 & $69.95 x$ \\
\hline xilotacuirtls & 41 & $n$ & 4 & 2242 & 4924 & 674 & 843 & 3609 & 445 & 282 & 5090 & 1921 & 1511 & 26580 & 28091 & $61.61 \mathrm{x}$ \\
\hline xalliturevotipan & 56 & 87 & 442 & 4348 & 3975 & 2066 & 639 & 874 & 4314 & 1447 & 11170 & 1152 & 1370 & 25935 & 31355 & $70.84 x$ \\
\hline Xiil Caloulalogn & 32 & 67 & 43 & 8012 & 1683 & 753 & 753 & 929 & 622 & 493 & 7159 & 964 & 1771 & 21168 & 22939 & $53.35 \mathrm{x}$ \\
\hline Xnv Tlaxso & 46 & $n$ & 45 & 7263 & 3071 & 1421 & 802 & 859 & 18 & 7210 & 6416 & 580 & 1286 & 29475 & 30761 & $66.70 \mathrm{x}$ \\
\hline XV Aplizsco Centro Norte & 31 & 70 & 46633 & 5588 & 3143 & 2365 & 968 & 792 & 3830 & 1556 & 5560 & 1031 & 1415 & 24833 & 26248 & $56.29 x$ \\
\hline MV Aplace Sureste & 33 & $\pi$ & 51474 & 9487 & 2396 & 2915 & 817 & 877 & 4279 & 1260 & 6678 & 1970 & 1653 & 26679 & 31332 & $60.87 x$ \\
\hline Milxalortoc & 50 & 83 & 45 & 9590 & 2662 & 852 & 473 & 46 & 2418 & 5436 & 858 & 1284 & 1516 & 31748 & 33264 & $73.17 \times$ \\
\hline MVIII Huanta Centro Oriente. & 32 & 65 & 40418 & 7257 & 3374 & 1339 & 639 & 971 & 1604 & 1560 & 5151 & 539 & 1209 & 22434 & 23643 & $58.50 x$ \\
\hline Xox Huamanth Oeste & 38 & 76 & 45640 & 5493 & 5629 & 1324 & 650 & 1527 & 2476 & 1531 & 78005 & 2138 & 1638 & 285573 & 30211 & $66.19 \times$ \\
\hline Totales & 5608 & 1304 & 836909 & 99871 & 89992 & 33282 & 22932 & 34829 & 50242 & 39307 & 118524 & 21965 & 25637 & 510949 & 536581 & 6.111\% \\
\hline
\end{tabular}

Fuente: Instituto Tlaxcalteca de Elecciones (2013).

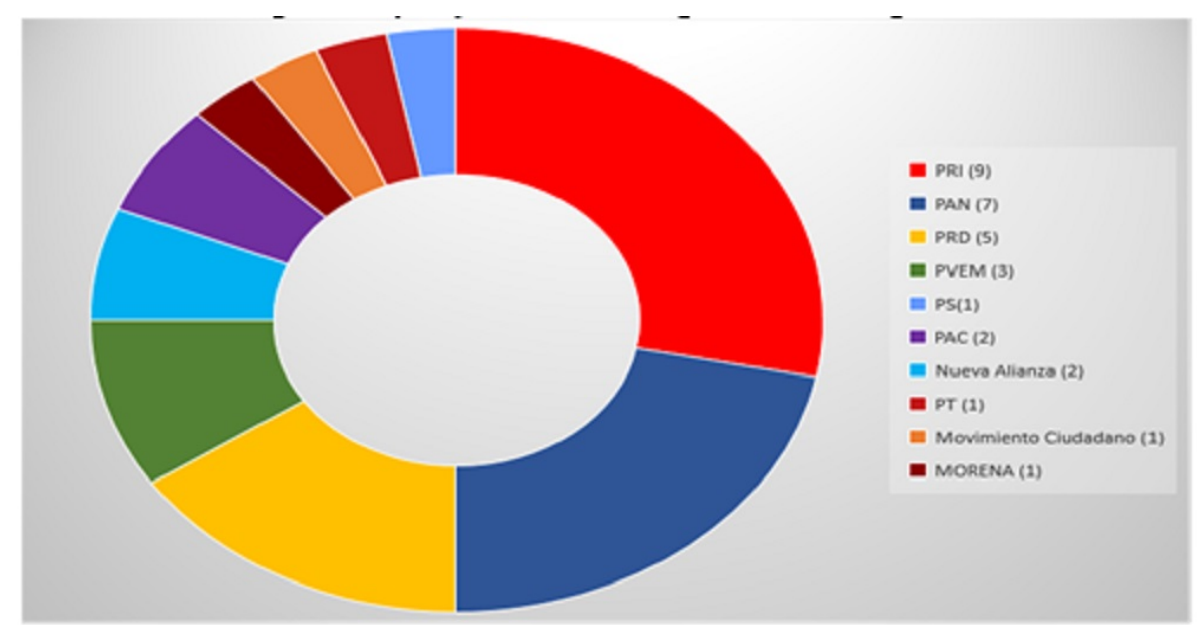

Gráfica 4.

Integración por partido, LXI Legislatura, Congreso de Tlaxcala

Fuente: elaboración propia, con base en información relativa a la LXI Legislatura Congreso del Estado de Tlaxcala.

Asimismo, y como un aspecto muy importante derivado de los resultados electorales con efectos en la gobernabilidad estatal, el vínculo entre el congreso y el ejecutivo constituye un elemento fundamental en la correlación de fuerzas políticas que puede fortalecer o debilitar al gobierno en turno; es decir, en la medida en la que el ejecutivo tiene un congreso a favor y coincidente con el partido que lo abanderó y llevó al triunfo, las agendas de gobierno transitan de manera más "fluida" o no. 


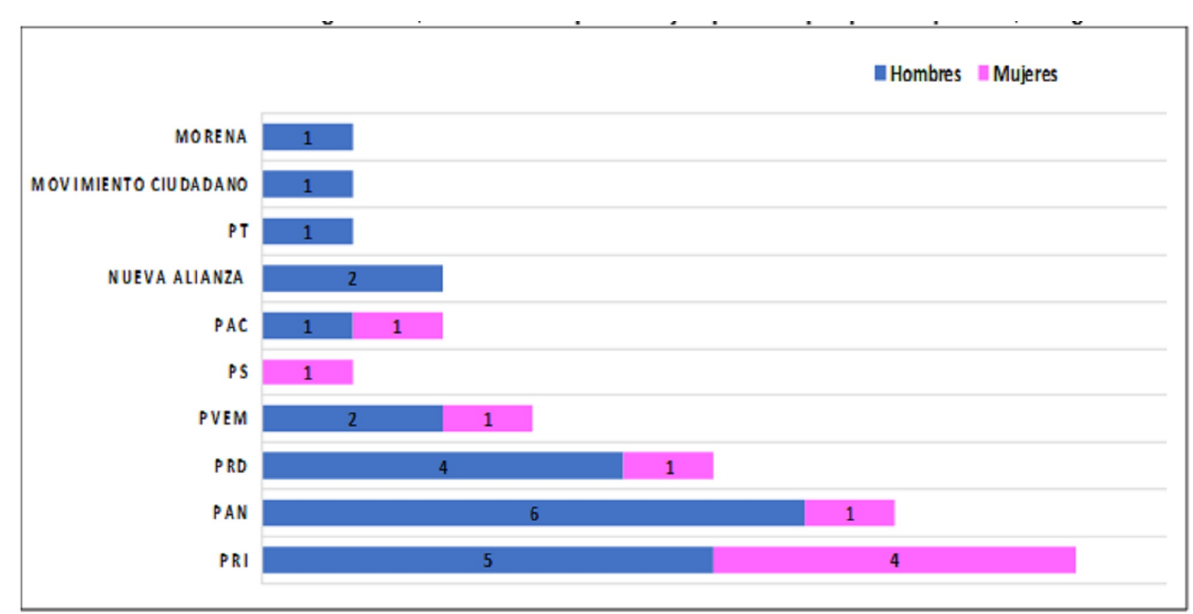

Gráfica 5.

Grupos Parlamentarios de la LXI Legislatura, 2013-2017. Diputados

y Diputadas por partido político, Congreso del Estado de Tlaxcala

Fuente: elaboración propia, con base en información relativa a los Grupos Parlamentarios de la LXI Legislatura en Tlaxcala.

Cada vez más y con una frecuencia generalmente esperada, los resultados electorales presentan gobiernos divididos que no brindan resultados; cada vez y con más frecuencia se acusa a los gobiernos de "simulaciones", sobre todo porque hoy difícilmente los congresos se convierten en un real contrapeso en torno a las decisiones que toman los ejecutivos, respecto de las acciones y destinos especialmente de los presupuestos a nivel local.

La integración de mayorías y minorías en los congresos claramente juegan un papel fundamental en la conformación del poder, tanto a nivel nacional como local. Los congresos son el espacio donde naturalmente se predibujan los escenarios de estabilidad o confrontación que, para Tlaxcala, y en específico durante la LXI Legislatura (2013-2017), que es el caso que nos ocupa, claramente no hubo confrontación, sino acompañamiento sin conflicto. A pesar de haber sido electos diputados y diputadas por 10 partidos políticos diferentes, lo que podría apuntar a una clara pluralidad política con debate de ideas y posturas diferenciadas en torno al desarrollo en Tlaxcala, no fue así. En dicha Legislatura, la mayoría la ostentó el PRI que, junto con los partidos que tradicionalmente le acompañaban (PVEM, Nueva Alianza), resultó en un periodo de gobierno terso, donde las agendas e iniciativas del ejecutivo podían eventualmente retrasarse, pero al final transitar sin mayor discusión (ver Gráfica 4).

Tlaxcala ha experimentado alternancias en todos los niveles de elección y con los tres partidos políticos más importantes (PRI, PAN y PRD), sin mencionar a MORENA que, hasta la elección de 2010, no existía como fuerza política; sin embargo, el "transfuguismo político" ha sido la marca que sella los resultados elección tras elección. En este escenario, el activismo político de las mujeres en la entidad sobre todo a nivel de elección a gobernador, ha contado con la participación de mujeres de forma trascendente en las últimas tres elecciones, no sólo por el número, sino porque efectivamente se convierten en candidatas que en 
los resultados son altamente competitivas, lo cual será objeto de otra investigación.

La participación de las mujeres en los partidos políticos en el Congreso del Estado fue claramente insuficiente; en la LXI Legislatura, de 32 diputaciones (19 mayoría relativa y 13 de representación proporcional), sólo nueve de ellas la ocuparon mujeres. En la integración, sólo el PRI fue, en su momento, el único partido que cumplió con lo pautado por la Ley Electoral, respetando la cuota establecida de $40 \%$ mujeres y $60 \%$ hombres; en el resto hay claramente inequidad en la integración y participación de mujeres diputadas frente a hombres diputados (ver Gráfica 5).

\section{Nivel académico y perfil profesional, de las y los legisladores}

La Constitución Mexicana no excluye ni limita la participación para el desempeño de un cargo público de elección, en este caso de una diputación, a cualquier ciudadano mexicano que cumpla los requisitos establecidos en el art. 55(17); dicho artículo no establece en ningún apartado que el funcionario o funcionaria deba cubrir algún nivel académico ni haber tenido experiencia profesional para desempeñar su cargo; sin embargo, y más allá de lo que la ley establece, es importante analizar el nivel y preparación que dichos servidores presentan al momento de desempeñarse en el cargo de diputados en tanto dicho cargo requiere de un conocimiento mínimo suficiente para legislar en torno a los diversos temas y problemáticas, que deben ser atendidas y normadas para la pacífica convivencia social con respeto al Estado de Derecho en el país.

El promedio de edad de las diputadas de la LXII legislatura es de 49 años, oscilando entre los 26 y 62 años, por lo que encontramos participación de mujeres jóvenes como maduras. Asimismo, el propósito de este apartado es presentar el perfil profesional de los diputados de la LXI Legislatura en Tlaxcala y contrastar el nivel de preparación que presentan las diputadas frente a los diputados.

En el caso de la LXI Legislatura en el estado de Tlaxcala, de 32 diputados que la integran: 20 de ellos tienen licenciatura, lo que representa el 62.5\%; mientras que apenas el 25\% (ocho) han obtenido una maestría. Es importante destacar que dos de ellos cuentan con nivel de secundaria (6.2\%), uno con nivel de preparatoria técnica y uno más no reporta nivel académico alguno (ver Gráfica 6). Como se ha mencionado antes, en los requisitos legales para acceder a un cargo público de representación (diputación) no se establecía ningún nivel académico específico, lo cierto es que el nivel académico puede eventualmente evidenciar no sólo el número de iniciativas que pueden presentarse sino la calidad, eficacia y eficiencia, respecto del trabajo y consecuentemente en el desempeño parlamentario de dicha legislatura en la entidad. 


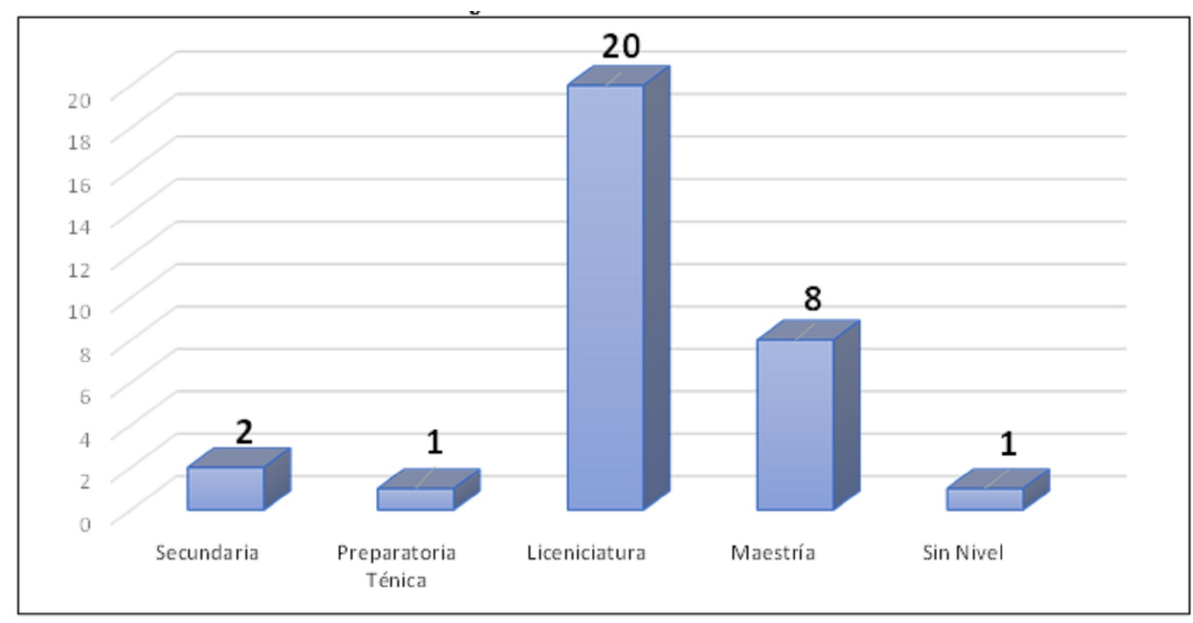

\section{Gráfica 6}

Nivel Académico de Diputados y Diputadas, de la LXI Legislatura, Congreso del Estado de Tlaxcala Fuente: elaboración propia, con base en la información proporcionada por el $\mathrm{H}$. Congreso del Estado de Tlaxcala, relativa a los integrantes de la LXI Legislatura.

Entre los diputados, el derecho es la principal disciplina de estudio (10); el segundo bloque más numeroso agrupa dos disciplinas: ciencias de la educación (4) y administración y relaciones internacionales (4); un tercer bloque lo integran medicina y contaduría pública con dos legisladores cada una, y con un solo legislador, las disciplinas de trabajo social, ciencias políticas y administración pública, agronomía, arquitectura, economía y filosofía, dicha distribución puede observarse en la gráfica 7. Asimismo, las diputadas de la LXI presentan un nivel académico variado; sin embargo, todas presentan estudios superiores y de posgrado, cuatro con licenciatura, tres con maestría y una con doctorado (ver Cuadro 3).

El 72\% de los diputados (23) no cuenta con ninguna experiencia en legislativa, siendo apenas nueve de ellos (28\%) los que efectivamente cuentan con alguna experiencia legislativa previa al cargo (ver Gráfica 8); las nueve diputadas presentan algún tipo de experiencia política, derivada de su desempeño en diversos cargos en el ámbito público (ver Cuadro 4).

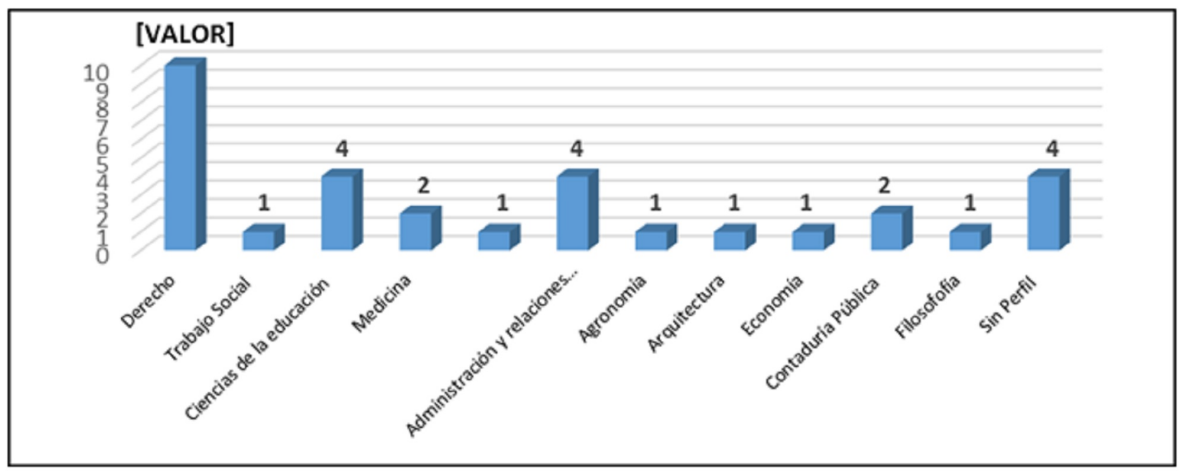

Gráfica 7.

Perfil Académico de Diputados y Diputadas, LXI Legislatura, Congreso de Tlaxcala

Fuente: elaboración propia, con base en la información proporcionada por el $\mathrm{H}$.

Congreso del Estado de Tlaxcala, relativa a los integrantes de la LXI Legislatura. 


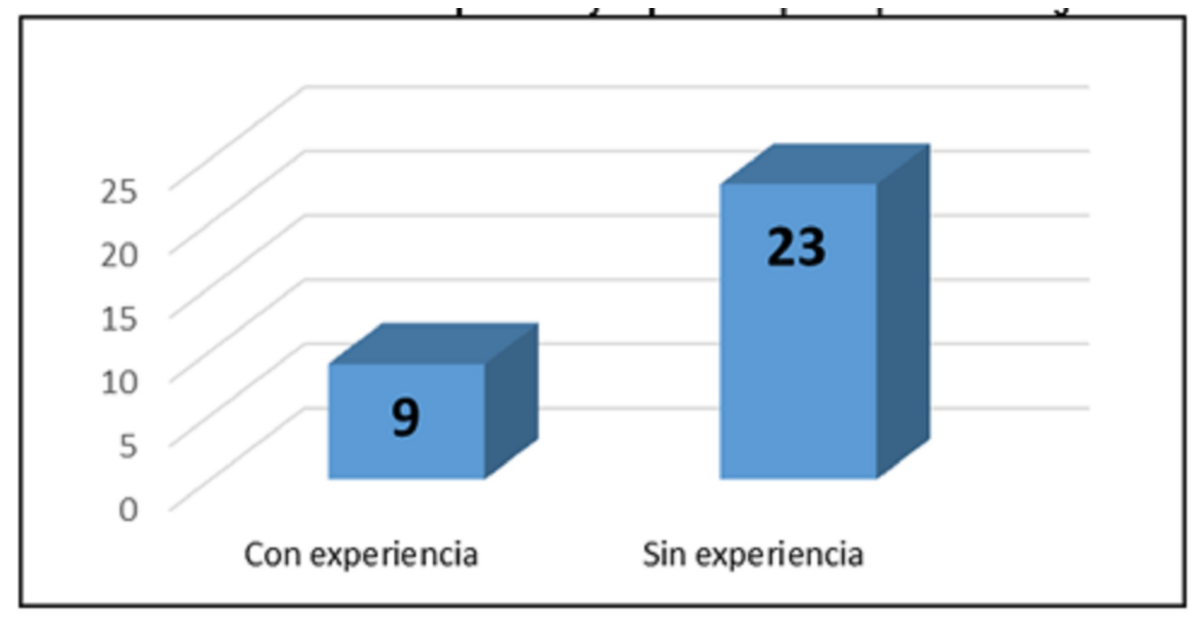

Gráfica 8.

Distribución de Diputados y Diputadas por experiencia legislativa

Fuente: elaboración propia, con base en la información proporcionada por el $\mathrm{H}$. Congreso del Estado de Tlaxcala, relativa a los integrantes de la LXI Legislatura. 


\section{Cuadro 3.}

Perfil profesional de las diputadas, LXII Legislatura, Tlaxcala

\begin{tabular}{|c|c|c|c|c|}
\hline Nombre & $\begin{array}{l}\text { Partido } \\
\text { Político }\end{array}$ & Distrito & $\begin{array}{l}\text { Fórmula de } \\
\text { Elección }\end{array}$ & $\begin{array}{l}\text { Nivel } \\
\text { Académico }\end{array}$ \\
\hline $\begin{array}{l}\text { Cecilia } \\
\text { Sampedro } \\
\text { Minor }\end{array}$ & PRI-PVEM & $\begin{array}{l}\text { Distrito } \\
\mathrm{X}\end{array}$ & $\begin{array}{l}\text { Mayoria } \\
\text { relativa }\end{array}$ & $\begin{array}{l}\text { Maestra en } \\
\text { Ciencias } \\
\text { Sociales, } \\
\text { Especialidad } \\
\text { en Cultura } \\
\text { Política }\end{array}$ \\
\hline $\begin{array}{l}\text { Juana de } \\
\text { Guadalupe } \\
\text { Cruz } \\
\text { Bustos }\end{array}$ & PRI-PVEM & $\begin{array}{l}\text { Distrito } \\
\text { II }\end{array}$ & $\begin{array}{l}\text { Mayoria } \\
\text { relativa }\end{array}$ & $\begin{array}{l}\text { Licenciada en } \\
\text { Derecho }\end{array}$ \\
\hline $\begin{array}{l}\text { María } \\
\text { Angélica } \\
\text { Zárate } \\
\text { Flores }\end{array}$ & PRI-PVEM & $\begin{array}{l}\text { Distrito } \\
\mathrm{XI}\end{array}$ & $\begin{array}{l}\text { Mayoria } \\
\text { relativa }\end{array}$ & $\begin{array}{l}\text { Maestra en } \\
\text { Derecho } \\
\text { Constitucional } \\
\text { y Amparo }\end{array}$ \\
\hline $\begin{array}{l}\text { María } \\
\text { Antonieta } \\
\text { Maura } \\
\text { Stankiewicz } \\
\text { Ramirez }\end{array}$ & PRI-PVEM & $\begin{array}{l}\text { Distrito } \\
\mathrm{XV}\end{array}$ & $\begin{array}{l}\text { Mayoría } \\
\text { relativa }\end{array}$ & $\begin{array}{l}\text { Licenciada en } \\
\text { Derecho, } \\
\text { Notaría y } \\
\text { Actuaria }\end{array}$ \\
\hline $\begin{array}{l}\text { Sinahi del } \\
\text { Rocio } \\
\text { Parra } \\
\text { Fernández }\end{array}$ & PRI-PVEM & $\begin{array}{l}\text { Distrito } \\
\text { XVII }\end{array}$ & $\begin{array}{l}\text { Mayoría } \\
\text { relativa }\end{array}$ & $\begin{array}{l}\text { Licenciada en } \\
\text { Derecho }\end{array}$ \\
\hline $\begin{array}{l}\text { Maria de } \\
\text { Lourdes } \\
\text { Huerta } \\
\text { Bretón }\end{array}$ & PAN & & $\begin{array}{l}\text { Representación } \\
\text { proporcional }\end{array}$ & $\begin{array}{l}\text { Licenciada en } \\
\text { educación } \\
\text { preescolar }\end{array}$ \\
\hline $\begin{array}{l}\text { Eréndira } \\
\text { Elsa } \\
\text { Carlota } \\
\text { Jiménez } \\
\text { Montiel }\end{array}$ & PRD & & $\begin{array}{l}\text { Representación } \\
\text { proporcional }\end{array}$ & $\begin{array}{l}\text { Maestra en } \\
\text { Gobierno, } \\
\text { Gestión y } \\
\text { Democracia }\end{array}$ \\
\hline $\begin{array}{l}\text { Evangelina } \\
\text { Paredes } \\
\text { Zamora }\end{array}$ & PAC & & $\begin{array}{l}\text { Representación } \\
\text { proporcional }\end{array}$ & $\begin{array}{l}\text { Doctora en } \\
\text { Derecho }\end{array}$ \\
\hline $\begin{array}{l}\text { Patricia } \\
\text { Zenteno } \\
\text { Hernández }\end{array}$ & PS & & $\begin{array}{c}\text { Representación } \\
\text { proporcional }\end{array}$ & $\begin{array}{l}\text { Licenciada en } \\
\text { Derecho }\end{array}$ \\
\hline
\end{tabular}

Fuente: elaboración propia, con base en la información proporcionada por el Congreso del Estado de Tlaxcala, 2017. 


\section{Cuadro 4.}

Experiencia en el espacio público de las diputadas, LXII Legislatura

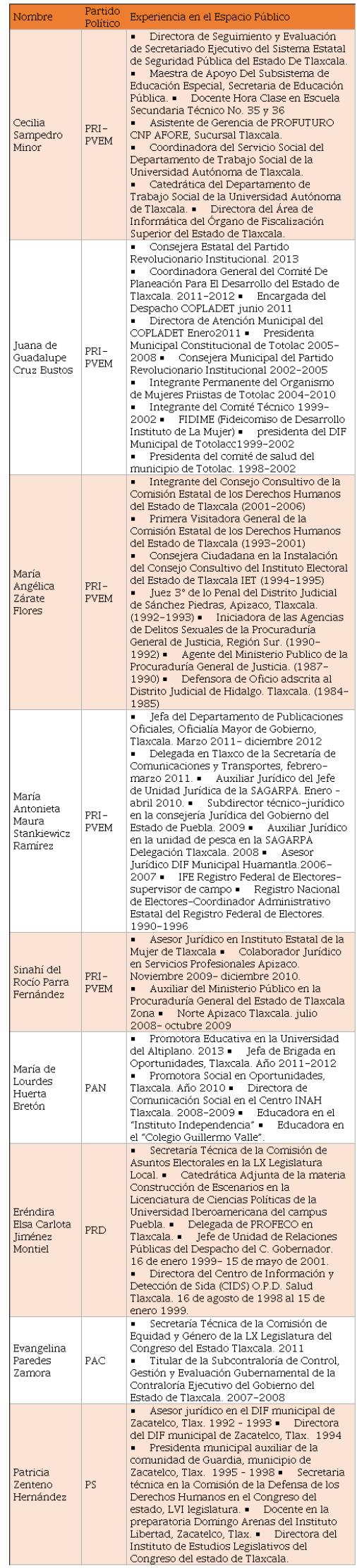




\section{Desempeño parlamentario y distribución del poder}

Como se ha mencionado, la LXI Legislatura en Tlaxcala se integra con apenas el $28 \%$ de mujeres diputadas (9) y el restante $72 \%$ son hombres (23), deficiencia que se ve reflejada en la asignación en los órganos de dirección; tal es el caso de la Junta de Coordinación y Concertación Política (JCCP), que durante los ejercicios legales de 2014 a 2016 fueron presididas por hombres, con una participación de entre una y dos mujeres diputadas por ejercicio legal, distribución que podemos observar en el cuadro 5. De igual forma, de las 14 mesas directivas que entre el 31 de diciembre de 2013 al 30 de diciembre de 2015 estuvieron activas, sólo cuatro de ellas fueron presididas por mujeres (10), el resto fueron presididas por diputados (ver Cuadro 6).

\section{Cuadro 5.}

Junta de Coordinación y Concertación Política, LXI Legislatura

\begin{tabular}{|c|c|c|c|c|}
\hline \multirow{9}{*}{$\begin{array}{l}\text { Grupos } \\
\text { Parlamentarios }\end{array}$} & \multicolumn{4}{|c|}{ Ejercicio Legal 2014} \\
\hline & Integrantes & Presidencia & Hombres & Mujeres \\
\hline & 9 & $\begin{array}{l}\text { Hombre } \\
\text { (PRI) }\end{array}$ & $\begin{array}{l}8 \text { (PRI, PRD, PVEM, } \\
\text { PAC, Movimiento } \\
\text { Ciudadano, PANAL, } \\
\text { PT) }\end{array}$ & 1 (PS) \\
\hline & \multicolumn{4}{|c|}{ Ejercicio Legal 2015} \\
\hline & Integrantes & Presidencia & Hombres & Mujeres \\
\hline & 10 & $\begin{array}{l}\text { Hombre } \\
\text { (PAN) }\end{array}$ & $\begin{array}{l}9 \text { (PAN, PRI, PRD, } \\
\text { PVEM, PAC, } \\
\text { Movimiento } \\
\text { Ciudadano, PANAL, } \\
\text { PT, PS) }\end{array}$ & 1 (PS) \\
\hline & \multicolumn{4}{|c|}{ Ejercicio Legal 2016} \\
\hline & Integrantes & Presidencia & Hombres & Mujeres \\
\hline & 11 & $\begin{array}{l}\text { Hombre } \\
\text { (PRD) }\end{array}$ & $\begin{array}{l}9 \text { (PAN, PRI, PRD, } \\
\text { PVEM, PAC, PVEM, } \\
\text { Movimiento } \\
\text { Ciudadano, PANAL, } \\
\text { PT y MORENA) }\end{array}$ & $\begin{array}{l}2 \text { (PRD } \\
\text { y PS) }\end{array}$ \\
\hline
\end{tabular}

Fuente: elaboración propia, con base en la información del H. Congreso del Estado de Tlaxcala, relativa a los integrantes de la LXI Legislatura. 


\section{Cuadro 6.}

Mesa Directiva, LXI Legislatura del Congreso de Tlaxcala

\begin{tabular}{|c|c|c|c|c|}
\hline Periodo & Integrantes & Presidencia & Hombres & Mujeres \\
\hline 31/diciembre/2013 al 15/mayo/2014 & 6 & Hombre & 2 & 4 \\
\hline $16 /$ mayo al 31 /julio/2014 & 4 & Hombre & 3 & 1 \\
\hline $1 \%$ agosto al $15 /$ diciembre/2014 & 6 & Hombre & 4 & 2 \\
\hline 16 al $30 /$ diciembre/2014 & 4 & Mujer & 2 & 2 \\
\hline 31/diciembre/2014 al 15/mayo/2015 & 6 & Hombre & 2 & 4 \\
\hline 16 /mayo al 31 /julio/2015 & 4 & Hombre & 4 & - \\
\hline $1^{\circ}$ al $10 /$ agosto/2015 & 6 & Hombre & 4 & 2 \\
\hline 11 /agosto al $19 /$ octubre/2015 & 6 & Hombre & 3 & 3 \\
\hline 20/octubre al $15 /$ diciembre/2015 & 6 & Mujer & 2 & 4 \\
\hline 16 al $30 /$ diciembre/2015 & 4 & Hombre & 4 & - \\
\hline $31 /$ diciembre/2015 al $15 /$ mayo/2016 & 6 & Mujer & 3 & 3 \\
\hline $16 /$ mayo al 31 /julio/2016 & 4 & Mujer & 3 & 1 \\
\hline $1 \%$ agosto al $15 /$ diciembre/2016 & 6 & Hombre & 4 & 2 \\
\hline 16 al $30 /$ diciembre/2016 & 4 & Hombre & 1 & 3 \\
\hline
\end{tabular}

Fuente: elaboración propia, con base en la información del H. Congreso del Estado de Tlaxcala, relativa a los integrantes de la LXI Legislatura.

En el Congreso del Estado de Tlaxcala existieron dos comités para el periodo en el que estuvo vigente la LXI Legislatura: el Comité de Administración y el Comité de Información. En el caso del primero y para cada año de ejercicio legal, éste contaba con presidencia, de los tres el primero de ellos en 2014 fue presidido por una diputada, siendo el único con una integración cercana a la equidad (4 mujeres y 5 hombres); el resto fueron presididos por hombres y con participación de entre dos y una diputada en dicho órgano (ver Cuadro 7). Respecto del Comité de Información, sólo hubo uno que estuvo vigente por todo el periodo de la legislatura y fue presidido por una diputada; es importante destacar que, en este caso, la integración fue equitativa; es decir, tres diputados y tres diputadas (ver Cuadro 8).

Sobre las comisiones que fueron formadas y estuvieron vigentes en dicha legislatura, fueron un total de 24 , de las cuales apenas seis fueron presididas por diputadas, el resto (18) fueron presididas por hombres. Dicha inequidad también se vio reflejada en la integración de dichas comisiones, donde la participación de las diputadas oscila entre una y cuatro, siendo la de mayor presencia y muy probablemente por el propósito mismo de la comisión, la de Igualdad de Género y en Contra de la Trata de Personas. En el cuadro 9 podemos observar a detalle la integración de las comisiones por total de integrantes, hombres, mujeres; por partido político; y la presidencia por género y por partido.

\section{Cuadro 7.}

LXI Legislatura, Congreso del Estado de Tlaxcala

\begin{tabular}{|l|l|l|l|l|}
\hline Comité de Administración & & & \\
\hline Año de ejercicio legal & Integrantes & Presidencia & Hombres & Mujeres \\
\hline 2014 & 9 & Mujer & 5 & 4 \\
\hline 2015 & 9 & Hombre & 7 & 2 \\
\hline 2016 & 6 & Hombre & 5 & 1 \\
\hline
\end{tabular}


Fuente: elaboración propia, con base en la información del H. Congreso del Estado de Tlaxcala, relativa a los integrantes de la LXI Legislatura.

\section{Cuadro 8.}

LXI Legislatura, Congreso del estado de Tlaxcala

\begin{tabular}{|l|l|l|l|l|}
\hline Comité de Información & Integrantes & Presidencia & Hombres & Mujeres \\
\hline Periodo & Mujer & 3 & 3 \\
\hline $13 /$ febrero/2014 al 30/diciembre/2016 & 6 & M & 3 & 3 \\
\hline
\end{tabular}

Fuente: elaboración propia, con base en la información del H. Congreso del Estado de Tlaxcala, relativa a los integrantes de la LXI Legislatura.

\section{Cuadro 9.}

Comisiones de la LXI Legislatura, Congreso del Estado de Tlaxcala

\begin{tabular}{|c|c|c|c|c|c|c|}
\hline $\mathrm{N}^{\circ}$ & F & 年 & & Mujes & & \\
\hline 1 & Asuntos Electorales & 5 & 4 & 1 & $\begin{array}{l}\text { PAN (2) PRI (1) Nueva Alianza } \\
\text { (1) }\end{array}$ & Hombre (PAN) \\
\hline 2 & Asuntos Municipales & 5 & 5 & - & PRD (2) PAN (2) PRI (1) & Hombre (PRD) \\
\hline 3 & Morilidad, Comunicaciones y Transporte & 5 & 5 & - & $\begin{array}{l}\text { PRI (1) Nueva Alianza (1) } \\
\text { PFEM (1) FRD (1) PAN (1) }\end{array}$ & Hombre $(\mathbb{P R I})$ \\
\hline$\frac{4}{5}$ & $\begin{array}{l}\text { Asuntos Migratorios } \\
\text { Derechos Humanos, Grupos Vulnerables y Derecho de }\end{array}$ & $\begin{array}{l}4 \\
8\end{array}$ & $\begin{array}{l}4 \\
6\end{array}$ & 2 & $\begin{array}{l}\text { PRI (2) PRD (1) MORENA (1) } \\
\text { MORENA (1) PRI (2) PVEM (1) }\end{array}$ & $\begin{array}{l}\text { Hombre (PRD) } \\
\text { Hombre (MORENA) }\end{array}$ \\
\hline & 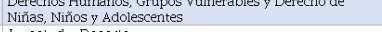 & & & & Nueva Alianza (1) PAC (1) & \\
\hline 5 & Juventud y Deporte & 3 & 2 & 1 & $\begin{array}{l}\text { Nuera Alianza (1) PRD (1) PRI } \\
\text { (1) }\end{array}$ & Hombre (Nueva Alianza) \\
\hline 7 & Educación, Cultura, Ciencia y Tecnologia & 5 & 4 & 1 & $\begin{array}{l}\text { Nueva Alianza (1) PRI (1) PAN } \\
\text { (1) FAC (1) Mor C Cuugadano (1) }\end{array}$ & Hombre (Nueva Alianza) \\
\hline 8 & Igualdad de Gènero y Contra la Trata de Personas & 4 & - & 4 & PVEM (1) RRD (1) PRI (1) PAN & Mujer (PYEM) \\
\hline 9 & Finanzas y Fiscalización & 8 & 6 & 2 & $\begin{array}{l}\text { (1) (1) PRI (2) Nueva Alianza } \\
\text { (1) FYEM (2) PRD (1) }\end{array}$ & Hombre (PAN) \\
\hline 10 & Fomento Agropecuario y Desarrollo Rural & 3 & 3 & - & PRI (1) PAN (1) MOT. & Hombre (PRI) \\
\hline 11 & Desarrollo Económico & 4 & 4 & - & $\begin{array}{l}\text { PRI (1) PAN (1) Nueva Alianza } \\
\text { (1) FD (1) }\end{array}$ & Hombre (PRI) \\
\hline 12 & $\begin{array}{l}\text { Instructora de Juicio Politico, Declaracion de Procedencia, } \\
\text { Defaftero }\end{array}$ & 3 & 1 & 2 & PRI (2) PVEM (1) & Mujer PRI) \\
\hline 13 & Obras Fúblicas, Desarrollo Urbano y Ecologia & 4 & 3 & 1 & $\begin{array}{l}\text { PVEM (1) FRD (1) PRI (1) Moy } \\
\text { Ciudadano (1) }\end{array}$ & Hombre (PVEM) \\
\hline 14 & $\begin{array}{l}\text { Puntos Constitucionales, Gobernación y Justicia y Asuntos } \\
\text { Politicos }\end{array}$ & 8 & 5 & 3 & $\begin{array}{l}\text { PRI (3) Nueva Alianza (1) } \\
\text { PVEM (1) PAN (2) PRD (1) }\end{array}$ & Mujer (PRI) \\
\hline 15 & Recursos Hidráulicos & 3 & 3 & 1 & PVEM (1) FRI (2) & Hombre PVEMi \\
\hline 16 & Salud & 3 & 2 & 1 & PRI (1) PVEM (1) PRD (1) & Hombre (PRI) \\
\hline 17 & $\begin{array}{l}\text { Protección Civil, Seguridad Pública, Frevención y } \\
\text { Readaptación ocial }\end{array}$ & 3 & 3 & - & PAN (1) PRD (2) & Hombre (PAN) \\
\hline 18 & $\begin{array}{l}\text { Trabajo, Competitividad, Seguridad Social y Previsión } \\
\text { social }\end{array}$ & 3 & 1 & 2 & PRI (2) PAC (1) & Mujer (PRI) \\
\hline 19 & Turismo & 3 & 3 & - & PRD (1) PVEM (1) PAC (1) & Hombre (PRD) \\
\hline 20 & Información Fública y Protección de Datos Personales & 8 & & 1 & $\begin{array}{l}\text { PAC (1) PRI (2) PAN (1) PYEM } \\
\text { (1) FRD (1) PI (1) }\end{array}$ & Hombre $(\mathbb{P A C})$ \\
\hline 21 & Medio Ambiente y Recursos Naturales & 5 & 3 & 2 & $\begin{array}{l}\text { PAN (2) PRD (1) PAC (1) } \\
\text { MORENA (1) }\end{array}$ & Hombre (PAN) \\
\hline 22 & Desarrollo Humano y Social & 3 & 1 & 2 & PAC (1) PRD (1) PAN (1) & Mujer $\mathbb{P A C}$ \\
\hline 23 & Fomento Artesanal y MIPYMMES & 3 & 3 & - & PRD (1) PAN (1) PRI (1) & Hombre (FRI) \\
\hline 24 & Comisión de la Famulia y su Desarrollo Integral & 3 & 1 & 2 & PAN (1) PRI (1) PAC (1) & Mujer (PAN) \\
\hline
\end{tabular}

Fuente: elaboración propia, con base en la información del H. Congreso del Estado de Tlaxcala, relativa a los integrantes de la LXI Legislatura.

En el contexto de la investigación, se realizaron entrevista a seis de las nueve exlegisladoras para conocer su opinión sobre algunos aspectos centrales de su trabajo. El instrumento recabó información sobre aspectos 
generales de tipo socioeconómico: perfil, conflictos internos en el partido dado su interés de participar siendo mujeres, fricciones con su bancada durante el desempeño del cargo, inequidad en la distribución de las cargas de trabajo entre diputados vs diputadas, dobles jornadas entre el espacio público y privado, acoso, discriminación, auto exigencia para el desempeño de un cargo público, persistencia de los estereotipos de género, entre otros.(18)

Inicialmente se les preguntó si consideraban que la carga de trabajo legislativo era inequitativa entre diputados y diputadas (mujeres contra hombres), asignándose comisiones con mayor carga de trabajo a mujeres, aunque no en aquellas comisiones que fueran de mayor importancia e interés para la legislatura. En este aspecto, las entrevistadas opinaron que:

"Las comisiones con alto indice de trabajo estuvieron presididas por mujeres, asi que la carga de trabajo era correspondiente. Otras comisiones como la de finanzas, no fue permitida la inserción del manejo por una mujer, fueron hombres quienes se encargaron de dicha comisión y que también representa una gran carga laboral" (Entrevistas, 2017).

"El trabajo siempre se sitúa en la producción y en la velocidad que uno lo haga. Las mujeres somos de trabajo, creativas y somos comprometidas con el trabajo" (Entrevistas, 2017).

"Las comisiones con alto indice de trabajo estuvieron presididas por mujeres, asi que la carga de trabajo era correspondiente. Otras comisiones como la de finanzas, no fue permitida la inserción del manejo por una mujer, fueron hombres quienes se encargaron de dicha comisión y que también representa una gran carga laboral" (Entrevistas, 2017).

En este contexto, la opinión de la mayoría de las entrevistadas refería que las comisiones de menor importancia y con mayor carga de trabajo, eran encabezados por mujeres, reconociendo la disciplina y compromiso en el cumplimiento de su trabajo.

\section{Agenda legislativa y desempeño parlamentario}

El rendimiento parlamentario presenta un aumento entre el primero y segundo año de la legislatura en funciones (2014-2015), y una clara disminución en 2015, esto derivado tanto del cierre del propio Gobierno del Estado (2010-2016) como de la proximidad de elecciones locales, donde muchos de los legisladores/as en funciones empezaron a tener movilidad y en algunos casos a pedir licencia al cargo para presentarse como candidatos a otros cargos de elección en la entidad; sin embargo, en la formulación y presentación de iniciativas, de las 135 iniciativas que a lo largo del periodo presentaron las exlegisladoras: poco más del 38\% (52) las presentó una exlegisladora plurinominal por el PRD y poco más del 61\% (83) el resto de exlegisladoras; cuatro de ellas de la bancada del PRI presentaron en conjunto un total de 45 iniciativas (33\%); 14 (11\%) iniciativas una exlegisladora por el PAN; 5 (4\%) la exlegisladora del PVEM; 16 (12\%) iniciativas la exlegisladora por el PAC y apenas $3(2 \%)$ iniciativas la exlegisladora por el PT.

En este contexto, si bien hay rendimiento parlamentario de todas las exlegisladoras, se destaca en especial el de la diputada por representación 
proporcional del grupo parlamentario del PRD; su actividad frente al resto es importante, sobre todo durante los dos primeros años de la legislatura presentando 52 iniciativas, de las cuales sólo dos de ellas fueron aprobadas (ley de Sociedades de Convivencia Solidaria y ley de Voluntad Anticipada), siendo su año prolífico el 2015 con 31 iniciativas presentadas (ver Gráfica 9). En este contexto, la diputada por el PRD, frente al resto de diputados (hombres y mujeres) fue altamente productiva. Dicha diputada, en su informe legislativo al cierre de la legislatura, afirmó de su experiencia como diputada y paso por el congreso, que:

"Desafortunadamente, la distancia que existe entre el ser y el deber ser dentro del Congreso es amplia y contradictoria, ya que, lo que debiera ser una representación popular para evitar excesos del Ejecutivo, termina convirtiéndose en el facilitador de esos abusos, mismos que se legitiman con la construcción de mayorias parlamentarias que rebasan lo partidista o lo ideológico, ya que por lo general son logradas mediante acuerdos económicos" (19).

Si bien fue importante el desempeño de todas las legisladoras, el desempeño de la diputada del PRD se destaca no sólo en número, sino en la diversidad de temas que abordaron las iniciativas.

Durante su periodo como legisladora, propuso en 52 iniciativas: 14 nuevas leyes, 25 reformas a ordenamientos jurídicos locales y 13 acuerdos para solicitar la atención de diversas situaciones socio-jurídicas. Entre las temáticas en las que versaron sus iniciativas, están: iniciativas en materia civil y de orden social, cuyas leyes son de impacto directo en la cotidianidad de las personas y las familias; 12 iniciativas que corresponden a 4 nuevas leyes: Sociedades de Convivencia Solidaria; Voluntad Anticipada; Protección del Patrimonio de las Familias con Hijos en Etapa Escolar (Uniforme y Lista de Útiles Escolares); y Ley sobre Uso de Colores, Siglas y Símbolos en Edificios Públicos; y 8 reformas a ordenamientos jurídicos locales: Código Civil, Código de Procedimientos Civiles, Ley para Personas con Discapacidad y Ley de Protección Civil, en materias de: Matrimonio Igualitario; Juicio de Concordancia Sexo-Genérica; Tutela Preventiva; Hipoteca Inversa; Empleo y Pensión para Personas con Discapacidad; Capacitación para Primeros Auxilios de operadores de servicios; Alimentos para menores y Alineación Parental; sin embargo, y tal y como ella misma afirma:

\footnotetext{
"La mayoria de las cuales quedaron solo en manos de las comisiones ordinarias a que fueron turnadas, como de manera reprobable le sucede a las iniciativas que proceden de voces opositoras al grupo en ejercicio del poder público, por la simple razón de no aceptar nada que no venga del Ejecutivo Local, o de ignorar sin importar su trascendencia para la sociedad, a todo aquello que venga de quien no se somete ciegamente a la caprichosa y en ocasiones absurda voluntad de quienes temporal y circunstancialmente gobiernan con una visión patrimonialista y no con compromiso social" (20).
}

Asimismo, la misma exlegisladora presentó leyes relacionadas con los procesos electorales locales: siete iniciativas que corresponden a cuatro nuevas leyes: Nueva Ley de Instituciones y Procedimientos Electorales; Ley de Partidos Políticos del Estado; Ley de Candidaturas Independientes y Ley Orgánica del Tribunal Electoral del Estado; y tres reformas 
en materia electoral a: Constitución Política del Estado (presentada a nombre de la Comisión de Asuntos Electorales); Código Penal (delitos electorales) y Ley de Medios de Impugnación en Materia Electoral. También leyes relacionadas con la fiscalización de cuentas públicas, con un total de cuatro iniciativas: Nueva Ley de Fiscalización y Rendición de Cuentas Públicas y tres reformas a la Constitución del Estado; Ley Orgánica del Poder Legislativo y Ley Municipal. Seguidas por tres leyes relacionadas con el marco regulatorio municipal: dos nuevas leyes: Nueva Ley Orgánica Municipal; Ley de Deberes, Derechos y Atribuciones de los Habitantes y Autoridades de Las Zonas Metropolitanas y Conurbadas del Estado; así como una reforma a la Constitución del Estado en la materia.

Presentó iniciativas respecto de leyes relacionadas con el marco regulatorio del Congreso Local: tres iniciativas que corresponden a dos nuevos ordenamientos: Nueva Ley Orgánica del Poder Legislativo y Nuevo Reglamento Interior del Congreso, y una reforma a la Ley Orgánica en la materia. Además, nueve leyes relacionadas con la planeación, y de estas surgió una nueva ley: Ley de Planeación Democrática y Contraloría Social para el Desarrollo del Estado de Tlaxcala y sus Municipios. Además de ocho reformas en materia de planeación: Constitución del Estado; Ley Orgánica de la Administración Pública; Ley Municipal; Ley Orgánica del Poder Legislativo; Reglamento Interior del Congreso; Ley de Fiscalización Superior; Código Financiero; Ley de Responsabilidades de los Servidores Públicos y Ley Laboral de los Servidores Públicos. También leyes relacionadas con el ramo penal: una Reforma al Código Penal del Estado de Tlaxcala en materia de feminicidio, además de 13 acuerdos presentados para solicitar la atención de diversas situaciones socio-políticas constantes; intervenciones relevantes ante el Pleno entre las que destacan 27. No sólo se observó un alto rendimiento parlamentario, sino la capacidad reflexiva y de análisis respecto de la coyuntura actual que vive México y Tlaxcala, y de la cual afirma:

"El desgaste de las instituciones y de quienes las han encabezado ha sembrado el hartazgo hacia ellos en el pueblo, quien empieza a mostrarse abierto a explorar opciones fuera de los partidos politicos sin mediar para ello mayor razón que la de probar algo diferente, pero sin calcular si esto pueda resultar más riesgoso aún que lo que padece en el presente. Quiénes nos dedicamos al ejercicio de la política debemos reflexionar sobre ello y tomar la decisión de renovar radicalmente la conducta mostrada por los partidos y sus dirigentes, bajo pena de que de no hacerlo estaremos condenados a ser relevados por completo de los espacios públicos, porque la realidad de la situación presente ya no admite conductas de opacidad, indefinición de principioso corruptelas, dignifiquemos el ejercicio de la politica por el bien de todos los mexicanos" (21).

Cabe resaltar que fue la única legisladora que presentó un informe final del cual se recogen las afirmaciones anteriores. Al solicitarle al congreso estatal los informes de todos los legisladores, el único recibido fue el de la exdiputada por el PRD. La exdiputada abandonó las filas del PRD el 17 de febrero de 2017; actualmente no está afiliada a ningún otro instituto político nacional o local. 
El segundo lugar lo ocupó la exdiputada del Partido Alianza Ciudadana (PAC), con 16 iniciativas presentadas entre 2014 y 2015, fundamentalmente como parte de las presentadas por su partido (PAC), entre las que destacan: reformas a la Constitución Política, al Código Civil, al Código Financiero, a la Ley de Ingresos y a la Ley de Aguas del Estado de Tlaxcala. Así como iniciativas relativas a la Ley de educación, Ley Reglamentaria de Fuegos Pirotécnicos, iniciativa para que el dos de abril se declare el día de las personas con condición de autismo y capacidades diferentes y la iniciativa de creación de la Ley de Atención y Protección a los Niños y Personas con Autismo y sus Familias. Del resto de exdiputadas (siete), el número de iniciativas presentadas oscila entre dos y 13 (como podemos observar en el cuadro 10), mismas que fundamentalmente se presentaron de forma conjunta con el resto de integrantes de su bancada.

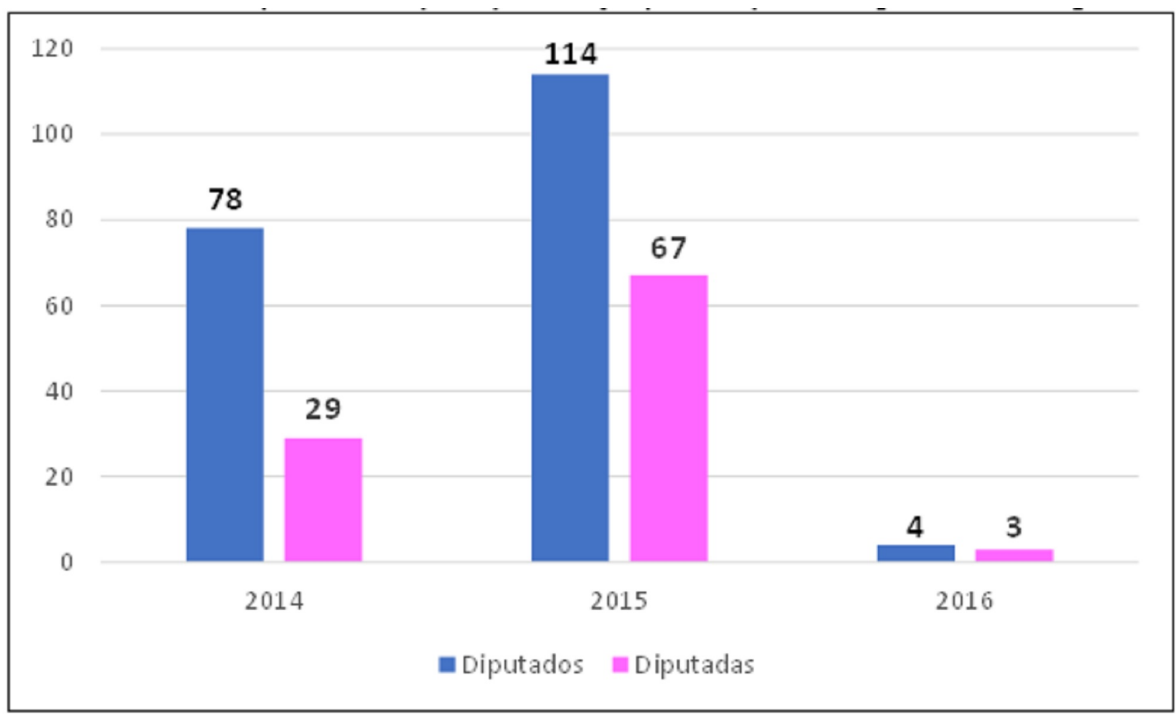

\section{Gráfica 9.}

Iniciativas presentadas por diputados y diputadas por año legislativo, LXI Legislatura Fuente: elaboración propia, con base en la información del H. Congreso del Estado de Tlaxcala, relativa a los integrantes de la LXI Legislatura. 
Cuadro 10.

Iniciativas de la LXI Legislatura

\begin{tabular}{|c|c|c|c|c|}
\hline \multirow[t]{2}{*}{ Partido } & \multirow[t]{2}{*}{ Nombre/Diputado/a } & \multicolumn{3}{|c|}{$\begin{array}{l}N^{\circ} \text { de Iniciativas } \\
\text { Presentadas }\end{array}$} \\
\hline & & 2014 & 2015 & 2016 \\
\hline \multirow{9}{*}{ PRI } & Salvador Cote Pérez & & 4 & \\
\hline & $\begin{array}{l}\text { Angel Xochitiotzi } \\
\text { Hernández }\end{array}$ & & 5 & \\
\hline & $\begin{array}{l}\text { Florentino Dominguez } \\
\text { Ordóñez }\end{array}$ & 2 & 6 & \\
\hline & $\begin{array}{l}\text { José Javier Vázquez } \\
\text { Sánchez }\end{array}$ & & 10 & \\
\hline & $\begin{array}{l}\text { José Heriberto Francisco } \\
\text { López Briones }\end{array}$ & & 4 & \\
\hline & $\begin{array}{l}\text { Juana De Guadalupe } \\
\text { Cruz Bustos }\end{array}$ & 1 & 5 & 1 \\
\hline & $\begin{array}{l}\text { María Angélica Zárate } \\
\text { Flores }\end{array}$ & 1 & 8 & 1 \\
\hline & $\begin{array}{l}\text { Sinahi Del Rocio Parra } \\
\text { Fernández }\end{array}$ & 2 & 7 & \\
\hline & Cecilia Sampedro Minor & 3 & 6 & \\
\hline \multicolumn{2}{|c|}{ Total de Iniciativas PRI } & 9 & 55 & 2 \\
\hline \multirow{7}{*}{ PAN } & $\begin{array}{l}\text { Julio César Álvarez } \\
\text { García }\end{array}$ & 4 & 15 & \\
\hline & Roberto Zamora Gracia & 2 & 8 & \\
\hline & $\begin{array}{l}\text { Iván Cuapantecatl } \\
\text { Trujillo }\end{array}$ & 2 & 7 & \\
\hline & $\begin{array}{l}\text { Humberto Agustín } \\
\text { Macias Romero }\end{array}$ & 2 & 7 & \\
\hline & $\begin{array}{l}\text { Ángelo Gutiérrez } \\
\text { Hernández }\end{array}$ & 3 & 11 & 1 \\
\hline & $\begin{array}{l}\text { José Gilberto Temoltzín } \\
\text { Martínez }\end{array}$ & 7 & 13 & 1 \\
\hline & $\begin{array}{l}\text { Maria De Lourdes } \\
\text { Huerta Bretón }\end{array}$ & 4 & 9 & 1 \\
\hline \multicolumn{2}{|c|}{ Total de Iniciativas PAN } & 24 & 70 & 3 \\
\hline \multirow{5}{*}{ PRD } & $\begin{array}{l}\text { Juan Ascención Calyecac } \\
\text { Cortero }\end{array}$ & & & \\
\hline & $\begin{array}{l}\text { Tomás Federico Orea } \\
\text { Albarrán }\end{array}$ & 1 & 3 & \\
\hline & $\begin{array}{l}\text { Santiago Sesin } \\
\text { Maldonado }\end{array}$ & 10 & 2 & \\
\hline & $\begin{array}{l}\text { Lázaro Salvador Méndez } \\
\text { Acametitla. }\end{array}$ & & & \\
\hline & $\begin{array}{l}\text { Eréndira Elsa Carlota } \\
\text { Jiménez Montiel }\end{array}$ & 21 & 31 & \\
\hline \multicolumn{2}{|c|}{ Total de Iniciativas PRD } & 32 & 36 & \\
\hline \multirow{3}{*}{ PVEM } & Albino Mendieta Lira & & 3 & \\
\hline & $\begin{array}{l}\text { Efraín Flores Hernández } \\
\text { (Suplente) Dip. Jaime } \\
\text { Piñon Valdivia) }\end{array}$ & 2 & 3 & \\
\hline & $\begin{array}{l}\text { María Antonieta Maura } \\
\text { Stankiewicz Ramíez }\end{array}$ & 1 & 4 & \\
\hline \multicolumn{2}{|c|}{ Total de Iniciativas PVEM } & 3 & 10 & \\
\hline \multirow{2}{*}{$\begin{array}{l}\text { Nueva } \\
\text { Alianza }\end{array}$} & Armando Ramos Flores & 1 & 1 & \\
\hline & Arturo Díaz Barranco & 1 & & \\
\hline \multicolumn{2}{|c|}{ Total de Iniciativas Nueva Alianza } & 2 & 1 & \\
\hline $\begin{array}{l}\text { Movimiento } \\
\text { Ciudadano }\end{array}$ & Refugio Rivas Corona & 9 & & \\
\hline \multicolumn{2}{|c|}{$\begin{array}{l}\text { Total de Iniciativas Movimiento } \\
\text { Ciudadano }\end{array}$} & 9 & & \\
\hline \multirow[t]{2}{*}{ PAC } & $\begin{array}{l}\text { Evangelina Paredes } \\
\text { Zamora }\end{array}$ & 10 & 6 & \\
\hline & Serafin Ortiz Ortíz & 10 & 6 & \\
\hline \multicolumn{2}{|c|}{ Total de Iniciativas PAC } & 20 & 12 & \\
\hline MORENA & $\begin{array}{l}\text { Baldemar Alejandro } \\
\text { Cortés Meneses }\end{array}$ & 4 & 6 & 2 \\
\hline \multicolumn{2}{|c|}{ Total de Iniciativas Morena } & 4 & 6 & 2 \\
\hline PT & Silvano Garay Ulloa & 8 & & \\
\hline \multicolumn{2}{|c|}{ Total de Iniciativas PT } & 8 & & \\
\hline PS & $\begin{array}{l}\text { Patricia Zenteno } \\
\text { Hernández }\end{array}$ & 1 & 2 & \\
\hline \multicolumn{2}{|c|}{ Total de Iniciativas PS } & 1 & 2 & \\
\hline \multicolumn{2}{|c|}{ Total de Iniciativas por año } & 112 & 192 & 7 \\
\hline
\end{tabular}


Fuente: elaboración propia, con base en la información del H. Congreso del Estado de Tlaxcala, relativa a los integrantes de la LXI Legislatura.

\section{Retos y perspectivas}

Como se mencionó, en este trabajo de investigación, además de analizar y describir el rendimiento parlamentario de las exlegisladora, se llevaron a cabo entrevistas (seis de nueve) con el propósito de conocer su opinión respecto del reto que significa, tanto su desempeño en cargos de elección popular y públicos frente a las cargas de trabajo y retos que enfrentan también en el espacio privado, lo que a decir de algunas, representa una doble carga, convirtiéndolas en mujeres "multifuncionales". En este sentido, las opiniones de las exdiputadas coincidían en que el asumir un cargo público de tanta importancia, les significaba una alta responsabilidad, sin dejar de reconocerse como "capaces" de desarrollar satisfactoriamente actividades tanto en el espacio público como en el privado:

"Es una labor muy respetable, al responsabilizarse de las actividades tanto del hogar como en su trabajo; las mujeres tenemos la capacidad de hacer muchas cosas a la vez, y hacerlas bien; tanto en el contexto laboral como del hogar. "Las mujeres no queremos no queremos quitarles espacios a los hombres, simplemente que nos reconozcan y que tengamos los mismos derechos para acceder a un cargo público y lo que conlleva como lo es el sueldo de forma equitativa” (Entrevistas, 2017).

"Las mujeres llevamos dobles o triples jornadas de trabajo, lo que sí es un abuso es no tener una remuneración en un trabajo doméstico” (Entrevistas, 2017).

Algunas de ellas consideraban que además de su capacidad para desempeñarse en ambos espacios, reconocían contar con habilidades como la "organización" y "disciplina", remitiéndoles buenos resultados en su trabajo diario en ambos espacios:

"El ajuste de las agendas permitió no desatender tanto las responsabilidades en el hogar, así como en el trabajo o en este caso siendo diputada en el congreso. Como mujeres si tiende a ser más organizadas, ha acoplarse a los horarios y actividades tanto del hogar como del trabajo" (Entrevistas, 2017).

"Es cuestión de organización, disciplina, de voluntad para hacer y sacar adelante las tareas encomendadas” (Entrevistas, 2017).

Además, se reconoce que la intención de participar conlleva el conocimiento de los retos que habrían de enfrentar en su desempeño en ambos espacios, como parte de las actividades y compromiso tanto en su desempeño en un cargo público como en el ámbito privado:

"Cuando uno decide ser servidor público, se sabe al compromiso que se enfrenta. El asumir el cargo de diputada, consiste más bien de decisión, responsabilidad y compromiso tanto en el cargo público como en el contexto personal/ familiar" (Entrevistas, 2017).

Al mismo tiempo, alguna de ellas reconoció asumir el rol estereotipado de las mujeres en una sociedad aún machista y hasta misógina, sobre todo tratándose de la actividad de mujeres en espacios públicos y como actores políticos con trascendencia en la toma de decisiones: 
"De acuerdo con los roles sociales establecidos, las mujeres siempre vamos a tener una mayor carga de trabajo dentro del hogar, tenemos la responsabilidad del cuidado de los hijos, la administración dentro del hogar; posiblemente eso merme un poquito el tener tiempo libre para desempeñar las funciones como uno quisiera. Se debe tomar conciencia, el trabajo de una diputación no es de horas, sino de un trabajo que requiero emplearse incluso todo el día de acuerdo con las jornadas laborales en el congreso del Estado" (Entrevistas, 2017).

Incluso algunas de ellas (no en todos los casos) expresaron contar con la ayuda de sus parejas y esposos para atender las actividades diarias a las que se enfrentaron por decisión personal, sin dejar de resaltar la posibilidad siempre presente de conflicto:

"Yo tuve la fortuna de tener a mi esposo que le gusta la política y que me fue sobrellevando, apoyando en la organización y realización de las actividades, sin embargo, lo difícil es cuando no tienes a un compañero que te apoye y existe la posibilidad de que termines limitándote o sacrificando algo de tu interés" (Entrevistas, 2017).

En este contexto se les preguntó si ellas consideraban que el estereotipo de género aun predomina en el espacio público, considerándolas por su propia condición de mujer: conciliadoras, sensibles, cuidadoras, incapaces de usar palabras insultantes, mesuradas, ordenadas, disciplinadas; en resumen, débiles, a lo que algunas contestaron:

"Las mujeres no somos débiles. Me siento insegura y con temores, de no hacer bien las cosas ya que, desde el seno familiar, una cultura machista por el padre desvalorizaba el hecho de ser mujer, al desear varones. Mi esposo no me dio esa credibilidad o voto de confianza, para ser secretaria general de un candidato, sin embargo, aprendí y se dio la oportunidad de tomar otros cargos importantes como ser diputada plurinominal" (Entrevistas, 2017).

Sin embargo, tres de ellas opinaron que los estereotipos ya no son tan evidentes; afirmaron que cada vez más y con mayor frecuencia se reconocen las capacidades que como mujeres deben desarrollar si su aspiración es desempeñarse en el ámbito público:

"Los estereotipos que envuelven a la mujer en el espacio público ya no permean tanto, y a que se han logrado los objetivos planteados al estar es estos espacios. La mujer debe valerse de una disciplina y no de una sumisión o perfil bajo para que no sea tomada en cuenta, sino que, debe ser constante, aguerrida para poder abrir espacios" (Entrevistas, 2017).

"Yo creo que las mujeres tenemos la capacidad suficiente para proponer, decidir, y en términos politicos la misma inteligencia que un hombre puede tener. Pero mucho depende de cómo nos ganemos ese respeto" (Entrevistas, 2017).

"Este estereotipo debe cambiar desde la actuación de las mujeres. Las mujeres necesitamos ser contundentes y más por el tiempo en el que vivimos, las palabras deben ser usadas en el momento exacto, no para insultar a nadie, sino para ser firmes $y$ serias, sin recurrir a ocurrencias. La voz de una legislador a debe ser muy firme, sobre todo seria y responsable, siendo de oposición o no, siendo muy objetiva, asumiendo las debilidades y las cuestiones que no favorezcan" (Entrevistas, 2017).

Adicionalmente, se les preguntó si durante el tiempo que duró su cargo como diputadas sufrieron algún tipo de acoso o discriminación por el sólo hecho de ser mujeres, a lo que contestaron que en algunos casos el acoso 
se presentaba ya sea en el contexto de algunas de las comisiones, pero en especial por parte de los medios de comunicación:

"Dentro de la comisión de finanzas y fiscalización, fue donde bubo fricciones fuertes, principalmente por compañeros varones, por no llegar a coincidir en algunas ideas" (Entrevistas, 2017).

"El unico caso fue por parte de los medios de comunicación, al existir una campaña de desprestigio sin argumentos" (Entrevistas, 2017).

Sobre ser objeto de algún tipo de discriminación, las exdiputadas en algunos casos y de forma indirecta, responsabilizan como el origen de ésta a los hombres y en otros, asociaron la discriminación al propio desempeño de sus cargos en el legislativo:

"En el tema politico, sabemos que es una lucha de intereses, en el cual se debe saber manejar las situaciones y de donde provienen dichas situaciones" (Entrevistas, 2017).

"Al inicio tal vez si se sentía, ya que a las mujeres se les resta un poco de importancia al momento de tomar decisiones" (Entrevistas, 2017).

"En la mayoria de las ocasiones fue más bien un hostigamiento politico" (Entrevistas, 2017).

"No como tal discriminación, sino el ejercicio de malas prácticas; es decir, donde sean varones los que tomen los acuerdos" (Entrevistas, 2017).

La aplicación del instrumento y las respuestas de las entrevistadas, permite constatar que si bien la presencia y participación de las mujeres en el espacio público, y en este caso como legisladores de un congreso estatal, cada vez es un hecho frecuente y ahora natural, lo cierto es que los espacios de decisión de mayor impacto, visibilidad y trascendencia siguen siendo reservados para los hombres. A las mujeres, si bien se les reconoce la disciplina y compromiso en el cumplimiento del trabajo, se les continúan asignando cargos que requieren mayor esfuerzo por la carga de trabajo y responsabilidades en espacios asociados "tradicionalmente" a su rol de género; y si bien durante el periodo analizado se presentaron casos notables de exlegisladoras con alto rendimiento parlamentario, lo cierto es que al final no hubo una correlación positiva entre el número y tipo de iniciativas presentadas con la aprobación de las mismas.

\section{Conclusiones}

Los estudios, que a lo largo de la historia se han hecho centrando como objeto de estudio a las mujeres, se ubican en dos orientaciones principales: 1) aquellas relativas a documentar sus condiciones de vida, trabajo, cultura y comportamiento; y 2) aquellas que analizan las condiciones de subordinación a las cuales se ven sometidas en lo político, social, económico, cultural y hasta psicológico, esto tanto en el espacio público, privado e incluso el íntimo (22). Este trabajo procura hacer una aproximación de ambos con el propósito final de comprender la realidad de la participación y desempeño de las mujeres que, ganando cargos de elección popular, asumen una serie de retos tanto en su vida pública como privada.

En este contexto, el análisis sobre órganos legislativos generalmente atrae reflectores en relación a aquellas decisiones que de forma plenaria 
tienen impacto sobre la vida de los ciudadanos; sin embargo, en pocas ocasiones se conoce el funcionamiento de los órganos internos de gobierno y menos aún, en cómo se establece la distribución de dirección por género de dichos órganos. En este trabajo, se propuso como objetivo hacer un análisis mixto (cuantitativo y cualitativo) que, partiendo de un caso particular, ofrezca mayores elementos para explicar la realidad de la participación política, desempeño y percepción de las mujeres en el espacio público en relación al privado.

La demanda y defensa histórica de las mujeres por el respeto a la equidad en sus derechos, ha trastocado y transformado el andamiaje institucional y normativo en México y el mundo. El activismo y persistencia de las mujeres ha tenido importantes logros que han desencadenado como en efecto dominó, su reconocimiento como actores sociales sujetos de derechos y obligaciones; en este escenario, la implementación del mecanismo de cuotas para garantizar la participación política de las mujeres fue el inicio de lo que hoy en México es norma: la paridad $50 / 50$ en el registro de candidaturas por parte de los partidos políticos. Sin embargo, la norma como un instrumento pragmático debe obligar a la reflexión en torno a la realidad que, en los hechos, obstaculizan la participación plena de las mujeres en las decisiones de gobierno; en este caso, en el órgano legislativo.

Este trabajo analizó concretamente el desempeño parlamentario de las exdiputadas de la LXI Legislatura en el estado de Tlaxcala, periodo 2013-2016, y confirmando la mención anterior, se consideró importante no sólo hacer un análisis de tipo cuantitativo, sino un trabajo mixto que mostrara las condiciones de equidad sustantiva en las que ejercen sus cargos, describiendo y contextualizando su trabajo y desempeño legislativo en dicho periodo.

Si bien las exlegisladoras objeto de este análisis fueron electas un año antes de que se promulgara la paridad 50/50 con la Reforma Política de 2014, el trabajo se muestra oportuno en la idea de motivar el desarrollo de un trabajo posterior de carácter comparado, que permita contrastar los resultados tanto en el desempeño parlamentario como en los retos a los que de manera individual se enfrentan las mujeres de la siguiente legislatura. Por otra parte, es importante destacar que la Reforma Política, en lo relativo a la paridad, se ha traducido en la generación de nuevos mecanismos de discriminación utilizados por los partidos políticos hacia las mujeres que, en muchos casos, continúan siendo sólo parte de las bases operativas utilizables y descartables del partido, en la medida en que estos son entidades autónomas que autorregulan su vida interna, donde las mujeres se ven excluidas de los espacios de decisión.

Sin embargo, y no menos importante, este trabajo también versa sobre el espacio privado e íntimo, donde las mujeres duplican sus cargas de trabajo y responsabilidades, haciendo aún más compleja (pero no por ello menos exitosa) la labor de las mujeres en los diversos espacios públicos del país. En este contexto, es importante mencionar que, en muchos casos, las mujeres no han logrado romper los "techos de cristal" ni superar "los 
pisos engomados", como un mecanismo de autocensura que les impide participar en la vida pública, pues tal y como afirman Llanos y Sample:

"La democracia paritaria no pretendia reemplazar a la democracia representativa y plural sino enriquecerla, posibilitando que las ciudadanas accedieran a la promesa incumplida del carácter universal del principio de igualdad que extiende los derechos a todas las personas sin distinción; sin embargo, ello se ha transformado en una nueva meta a alcanzar, pues en términos prácticos aún no se cumple"(23)

Los resultados de este trabajo confirman que, por un lado, la participación de las mujeres en cargos de elección está en un tránsito hacia la normalización en cuanto número; por el otro, persiste la desigualdad de género al interior de la legislatura, traduciéndose en cargas inequitativas del trabajo que se reflejan en: 1) la integración del propio congreso con perfiles diferenciados entre diputados y diputadas: edad, nivel educativo y experiencia política; 2) la distribución inequitativa en la asignación de dirección en los órganos de gobierno y comisiones internas, ya que los diputados conservan los cargos relevantes, así como las comisiones estratégicas; y 3) las agendas legislativas diferenciadas entre los géneros, donde se continúa asignando a las mujeres temas relacionados con su "rol de género".

En el caso del Congreso del Estado, la participación de las mujer no es distinta a la de otras regiones del país; la participación, como se ha dicho antes, se sujetaba y limitaba a lo establecido por las "cuotas de género", que si bien se implementaron en 2002, en Tlaxcala desde 1968 hasta 2017 la participación de mujeres legisladoras ha oscilado entre una y nueve, siendo justamente la LXI Legislatura la de más alta inclusión con nueve: cinco de ellas electas por la fórmula de mayoría relativa y cuatro por representación proporcional.

El estudio refleja que el promedio de edad de las legisladoras es de 49 años, encontrando participación de mujeres de entre 26 y 62 años de edad. Respecto al nivel académico de los 32 congresistas de la LXI Legislatura (hombres y mujeres): ocho de ellos cuentan con posgrado, 20 con estudios superiores, tres reportaron nivel básico y uno de ellos no reportó nivel educativo; en el caso de las diputadas: todas (9) reportaron contar con estudios superiores y de posgrado (una con doctorado, tres con maestría y cinco con licenciatura).

Durante dicha legislatura, los órganos de poder interno integraron la participación de las legisladoras de forma diferenciada: en el caso de la de Junta de Coordinación y Concertación Política, ninguno de sus tres ejercicios legales estuvo presidida por una mujer y la participación por cada ejercicio no fue de más de dos mujeres en su integración; respecto a la Mesa Directiva, durante los 14 momentos en que estuvo activa, sólo en cuatro momentos (28\%) estuvo presidida por una mujer; de igual forma, el Comité de Administración, en sus tres momentos, sólo durante el primer año (2014) estuvo presidido por una mujer; únicamente el Comité de Información, durante todo el periodo de la Legislatura (2014-2016), estuvo presidido por una mujer, con una integración paritaria de tres hombre y tres mujeres. 
De las 24 comisiones que estuvieron activas durante el periodo de la LXI Legislatura, sólo seis fueron presididas por mujeres (Igualdad de Género y Contra la Trata de Personas, Instructora de Juicio Político, Declaración de Procedencia, Desafuero y Responsabilidad de Munícipes, Puntos Constitucionales, Gobernación y Justicia y Asuntos Políticos, Trabajo, Competitividad, Seguridad Social y Previsión Social, Desarrollo Humano y Social y Comisión de la Familia y su Desarrollo Integral); es decir, apenas el $25 \%$ de total. Asimismo, de las 295 iniciativas presentadas durante el periodo en funciones de la legislatura, poco más del 33\% (99) fueron hechas por las diputadas; de éstas, poco más del 47\% (47) correspondió a ocho diputadas con iniciativas asociadas fundamentalmente a las presentadas por bancadas de partido político, y poco más del 52\% (52) fueron presentadas de forma individual por la diputada por representación del PRD, que si bien fue el caso de mayor productividad, en la práctica sólo le fueron aprobadas dos durante dicha legislatura.

Como resultado de la investigación cualitativa, es posible confirmar que las exlegisladoras, a pesar de lograr arribar a cargos de elección y asumir la responsabilidad pública que éste conlleva, reconociéndose como "capaces" de desarrollar satisfactoriamente actividades tanto en el espacio público como en el privado, los retos en la realidad eran mayores, se tenían que convertir en mujeres "multifuncionales" capaces de atender responsabilidad asumidas en ambos espacios. Al mismo tiempo, las exlegisladoras se reconocen como mujeres con interés, disposición y disciplina, por adquirir nuevos conocimientos y habilidades de organización que les remitieran buenos resultados en su desempeño público. Sin embargo, según la opinión obtenida a través de las entrevistadas, la persistencia de una sociedad tradicional aun machista y misógina, sobre todo tratándose de la actividad de mujeres en espacios públicos y como actores políticos con trascendencia en la toma de decisiones, es un elemento que puede convertirse en un obstáculo que impide su desarrollo profesional y como servidoras públicas, aunque al mismo tiempo, afirmaron que si bien lo hacía más complejo estableciendo roles estereotipados para las mujeres, no necesariamente era infranqueable.

Todas ellas expresaron que participar en el espacio público y como legisladoras, fue una decisión personal asumiendo que ello podía generar conflictos con sus parejas en la vida privada; sin embargo, ello no significó claudicar en su propósito, al contrario, asumieron de facto que dicha decisión implicaría dobles cargas de trabajo y aunque tres de ellas opinaron que si bien los estereotipos existen, escalando incluso a la violencia política, cada vez más y con mayor frecuencia se reconocen las capacidades que como mujeres pueden desarrollar si su aspiración es desempeñarse en el ámbito público.

El resultado de la investigación mostró que, si bien hay presencia y participación de las mujeres en el espacio público, y en este caso en un congreso local, los espacios de decisión de mayor impacto, visibilidad y trascendencia siguen siendo reservados para los hombres, en este 
caso visibilizado a través de la asignación de los órganos de gobierno internos. A las mujeres legisladoras, si bien se les reconoce disciplina y compromiso en el cumplimiento del trabajo, se les continúa asignando cargos y responsabilidades en espacios asociados "tradicionalmente" a su rol de género; y si bien durante el periodo analizado se presentaron casos notables de exlegisladoras con alto rendimiento parlamentario, lo cierto es que al final no hubo una correlación positiva entre el número y tipo de iniciativas presentadas con la aprobación de la mismas.

Es claro que las mujeres tlaxcaltecas que deciden participar en la vida pública del estado ven duplicadas y hasta triplicadas sus cargas de trabajo que se dividen entre el espacio público, privado e incluso íntimo. Sin embargo, ello no ha sido un inhibidor para desmotivar su interés; al contrario, pareciera que cada vez es más intenso y que la Reforma Política de 2014 será otro elemento que sin duda permitirá el despegue de los porcentajes de participación de las mujeres en la política local. Aun así, no debemos olvidar que si bien la norma se ha ajustado a una realidad social de equidad con justicia, en la práctica persisten viejas tendencias que pretenden inhibir o desincentivar la participación de las mujeres, siendo un reto más al que enfrentarse, sobre todo desmitificando dichos como el de que "no hay mujeres"; al contrario, es un reto que las mujeres con aspiraciones deben afrontar, preparándose cada vez más para que su logro y desempeño cumplan con los márgenes de eficacia y eficiencia esperados. Una democracia representativa, equitativa y plural, se ha convertido en el objetivo a alcanzar en México y sus gobiernos locales. Los hechos deben trascender la norma, debe traducirse en algo más que la participación equitativa de hombres y mujeres en la toma de decisiones para el desarrollo de nuestra sociedad, debe ser una realidad numérica y práctica.

En Tlaxcala, desde la década de los 70, las elecciones locales han evidenciado que a pesar de las alternancias, persiste en la práctica y en todos los partidos la estrategia de una cultura política tradicional de tipo caciquil, clientelar y en muchos momentos misógina, donde a pesar de ello el activismo de las mujeres ha sido notable; si bien hoy tenemos un sistema de partidos más competitivo, una celebración de elecciones libres en el contexto de mayor libertad de expresión y con más mujeres participando en todos los niveles de elección, todavía hay mucho por hacer frente a la emergencia de una sociedad cada vez más organizada, demandante y participativa, pero sobre todo, decidida a hacer marcaje personal a los políticos, locales y nacionales, señalándoles en todo momento sus límites y deficiencias, ya sean hombres o mujeres.

\section{Referencias}

Código Federal de Instituciones y Procedimientos Electorales (COFIPE). Diario Oficial de la Federación (DOF), 2006, México. Recuperado de: http://www.diputados.gob.mx/LeyesBiblio/ abro/cofipe/COFIPE_abro.pdf

Entrevistas de profundidad realizadas a las exdiputadas de la LXI Legislatura del Congreso del Estado de Tlaxcala. Noviembre-diciembre 2017. Tlaxcala. 
Estatuto del Partido Acción Nacional (PAN) México, 2016.

Estatutos del Partido de la Revolución Democrática (PRD) México, 2015.

Grupos Parlamentarios LXI. Legislatura H. Congreso del Estado de Tlaxcala. Recuperado de (junio de 2017): http://www.congresotlaxcala.gob.mx/ inicio/index.php/integrantes-de-la-lxi-legislatura/

H. Congreso del Estado de Tlaxcala. Información relativa a los integrantes de la LXI Legislatura. Recuperado de (diciembre de 2017): http://www.congresotlaxcala.gob.mx/inicio/ index.php/comisiones-lxi-legislatura/

Instituto Electoral de Tlaxcala-Instituto Tlaxcalteca de Elecciones (IET-ITE) (2017). Resultados elecciones de gobernador 1992, 1998, 2004 y 2016. México. Recuperado de: http://www.itetlax.org.mx/

Instituto Nacional Electoral (INE). Estadísticas de Padrón Electoral y Lista Nominal. Corte al 2 de junio de 2017. Recuperado de: http://portalanterior.ine.mx/archivos3/portal/historico/contenido/ EstadisticasListaNominalyPadron_Electoral/

Instituto Tlaxcalteca de Elecciones (ITE) (2013). Recuperado de: http:// www.itetlax.org.mx/wp-content/uploads/2016/03/Resultados \%20Generales\%20Diputados2013.pdf

Legislaturas del Honorable Congreso del Estado de Tlaxcala. Recuperado de: http://congresodetlaxcala.gob.mx/historia/

Llanos, B. y Sample, K. 30 años de democracia: ¿En la cresta de la ola? Participación política de la mujer en América Latina. Instituto Internacional para la Democracia y la Asistencia Electoral (IDEA), Estocolmo, 2008. Recuperado de: http://www.americalatinagenera.org/ biblioteca/detalle.php?IDPublicacion $=779$

Partido Revolucionario Institucional (PRI) Reglamento para la Elección de Dirigentes y Postulación de Candidaturas, México, 2017.

"Ley de Instituciones y Procedimientos Electorales del Estado de Tlaxcala". Periódico Oficial del Gobierno del Estado de Tlaxcala, México, 2015a.

"Partidos Políticos para el Estado de Tlaxcala". Periódico Oficial del Gobierno del Estado de Tlaxcala, México, 2015b.

Reforma política de 2014. Disponible en: https://www.gob.mx/cms/uploads/ attachment/file/3080/

EXPLICACION_AMPLIADA_REFORMA_POLITICA_ELECTORAL.pdf

\section{Notas}

(1)Mujeres en Red. "Declaración de Seneca Falls. 1848”. Texto completo. La historia. Publicado en Mujeres en Red. El periódico feminista, 2000. Recuperado de (noviembre de 2018): http://www.mujeresenred.net/IMG/article_PDF/article_a2260.pdf

(2) Joe Freeman (1945). politóloga, escritora y abogada estadounidense. De las primeras activistas del movimiento de liberación de las mujeres en Estados Unidos durante la segunda ola del feminismo en los años 60 . Especialista en movimientos sociales y partidos políticos. Autora de varios textos históricos del feminismo

(3) Shulamith Firestone (1945-2012). Escritora feminista canadiense-estadounidense. cofundadora de tres grupos feministas radicales de Nueva York: New York Radical Women, Redstockings y New York Radical Feminists. Autora del libro "La dialéctica del sexo: el caso de la revolución feminista” publicado en septiembre de 1970. 
(4) De Barbieri, Teresita. Sobre la categoría género. Una introducción teóricometodológica. Revista Debates en Sociología 18, p. 146. Departamento de Ciencias Sociales de la Pontificia Universidad Católica del Perú (PUCP).

(5) Krook, Mona Lena. Quotas for Women in Politics, Gender and Candidate Selection Reform Worldwide, Nueva York, Oxford University Press, 2009.

(6) Palma Cabrera, E. y Cerva Cerna, D. La importancia de las instituciones y la organización de las mujeres. El cumplimiento de la cuota de género en las elecciones federales mexicanas de 2012. Política y Gobierno. (en línea) XXI (2). Recuperado de: http://www.redalyc.org/articulo.oa?id=60331855003

(7) El hecho se presentó el 03 de septiembre de 2009 cuando, después de haberse integrado el Congreso de la Unión después de la elección federal, se presentaron en principio diez solicitudes de diputados y diputadas del PRD, PT, PRI y PVEM ocho mujeres y dos hombres- quienes solicitaron al pleno, licencia "indefinida" para separarse de sus cargos, a estos 10 después se le sumaría otro caso, siendo en total 11 licencias solicitadas al pleno; sin embargo, el acto causó diversas reacciones que incluso llegaron a la indignación por varias causas, mismas que propiciaron un fuerte debate a través de medios y redes sociales, denunciando redes de intereses al interior de los propios partidos que efectivamente postulaban a mujeres como candidatas con suplentes hombres quienes las sucederían después y de manera definitiva en el cargo.

(8) Cazarín Martínez, Angélica. "Democracia, género y justicia electoral en México”. Cuadernos de divulgación de la justicia electoral No 2. Tribunal Electoral del Poder Judicial de la Federación (TEPJF), 2011. México.

(9) Movimiento de Regeneración Nacional (MORENA) fue el nombre que inicialmente enarboló como asociación civil en 2011 dedicada a impulsar la democracia y la defensa de la soberanía de México, siendo su líder Andrés Manuel López Obrador; nombre que conservó cuando el nueve de julio de 2014 obtuvo su registro como partido nacional ante el Instituto Nacional Electoral (INE).

(10) A nivel local, fue hasta 1979 cuando se eligió a la primera mujer gobernadora por el estado de Colima: Griselda Álvarez; después, en 1987 Beatriz Paredes lo haría por Tlaxcala; Dulce María Sauri en 1991 por Yucatán; Rosario Robles como Jefa del Distrito Federal en 1999; Amalia García en 2004 por Zacatecas; y más recientemente Ivonne Ortega en Yucatán en 2007; es decir, en el transcurso de 33 años de elecciones en México han habido apenas seis mujeres que encabecen gobiernos estatales frente 186 hombres gobernando el resto de los estados, lo que representa apenas el 3.1\% de representación femenina en dicho lapso de tiempo.

(11) Derivado de la reforma política local, decreto 118, aprobado el 30 de junio de 2015 por el Congreso del Estado, y con el propósito de homologación de las elecciones locales con las federales, el periodo de Marco Antonio Mena Rodríguez como gobernador tendrá una duración de 4 años con 8 meses.

(12) María de los Ángeles Grant Munive (10 de marzo de 1929). Primera mujer regidora en el Ayuntamiento de Tlaxco; primera diputada local en Tlaxcala (1965-1968) y primera legisladora federal por Tlaxcala abanderada por el Partido Revolucionario Institucional (PRI) (1970-1973).

(13) Ley de Instituciones y Procedimientos Electorales, 2015.

(14) Ley de Partidos Políticos para el Estado de Tlaxcala, 2015, en su art. 52.

(15) En los estudios de género, se denomina "techo de cristal” a la limitación velada del ascenso laboral de las mujeres al interior de las organizaciones. Se trata de un techo que limita sus carreras profesionales, difícil de traspasar y que les impide seguir avanzando. Es invisible porque no existen leyes o dispositivos sociales establecidos y oficiales que impongan una limitación explícita en la carrera laboral a las mujeres. 
(16) Las fuerzas que mantiene a miles de mujeres atrapadas en la base de la pirámide económica. El "suelo pegajoso" se refiere al trabajo maternal, trabajo conyugal y trabajo doméstico que imponen una "adhesividad" a las mujeres, por lo que consideran un esfuerzo adicional realizar una carrera laboral, y en suma desempeñarse en el espacio público y fuera del ámbito doméstico, situación que termina por generar sentimientos de culpa que las atrapan fuertemente como parte de los lazos afectivos.

(17)Artículo 55. Para ser diputado se requiere: I. Ser ciudadano mexicano, por nacimiento, en el ejercicio de sus derechos. II. Tener veintiún años cumplidos el día de la elección; III. Ser originario de la entidad federativa en que se haga la elección o vecino de esta con residencia efectiva de más de seis meses anteriores a la fecha de ella. Para poder figurar en las listas de las circunscripciones electorales plurinominales como candidato a diputado, se requiere ser originario de alguna de las entidades federativas que comprenda la circunscripción en la que se realice la elección, o vecino de ella con residencia efectiva de más de seis meses anteriores a la fecha en que la misma se celebre. La vecindad no se pierde por ausencia en el desempeño de cargos públicos de elección popular. IV. No estar en servicio activo en el Ejército Federal ni tener mando en la policía o gendarmería rural en el Distrito donde se haga la elección, cuando menos noventa días antes de ella. V. No ser titular de alguno de los organismos a los que esta Constitución otorga autonomía, ni ser Secretario o Subsecretario de Estado, ni titular de alguno de los organismos descentralizados o desconcentrados de la administración pública federal, a menos que se separe definitivamente de sus funciones 90 días antes del día de la elección. No ser Ministro de la Suprema Corte de Justicia de la Nación, ni Magistrado, ni Secretario del Tribunal Electoral del Poder Judicial de la Federación, ni Consejero Presidente o consejero electoral en los consejos General, locales o distritales del Instituto Nacional Electoral, ni Secretario Ejecutivo, Director Ejecutivo o personal profesional directivo del propio Instituto, salvo que se hubiere separado de su encargo, de manera definitiva, tres años antes del día de la elección. Los Gobernadores de los Estados y el Jefe de Gobierno de la Ciudad de México no podrán ser electos en las entidades de sus respectivas jurisdicciones durante el periodo de su encargo, aun cuando se separen definitivamente de sus puestos. Los Secretarios del Gobierno de las entidades federativas, los Magistrados y Jueces Federales y locales, así como los Presidentes Municipales y Alcaldes en el caso de la Ciudad de México, no podrán ser electos en las entidades de sus respectivas jurisdicciones, si no se separan definitivamente de sus cargos noventa días antes del día de la elección; VI. No ser Ministro de algún culto religioso, y VII. No estar comprendido en alguna de las incapacidades que señala el artículo 59. Diario Oficial de la Federación (DOF). Constitución Política de los Estados Unidos Mexicanos. 24 de febrero de 2017, p. 57. México. Recuperado de: http://www.diputados.gob.mx/ LeyesBiblio/pdf/1_240217.pdf [consultado 07 de julio de 2017].

(18) Entrevistas realizadas por Rodrigo Flores Sánchez (Becario). Entre el primero de noviembre de 2017 y el 31 de enero de 2018

(19) Jiménez Montiel, Eréndira Elsa Carlota. Informe Legislativo. Grupo Parlamentario del Partido de la Revolución Democrática. Congreso del Estado de Tlaxcala, LXII Legislatura, 2014-2016.

(20) Ibid.

(21) Ibid.

(22) De Barbieri, Op cit., p. 2.

(23) Llanos y Samples, 2013, p. 19.

\title{
Enlace alternativo
}

\author{
http://perio.unlp.edu.ar/ojs/index.php/cps/index (html)
}

